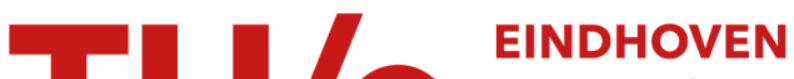 UNIVERSITY OF TECHNOLOGY
}

\section{Processing of thermoplastic polymers using reactive solvents}

Citation for published version (APA):

Meijer, H. E. H., Venderbosch, R. W., Goossens, J. G. P., \& Lemstra, P. J. (1996). Processing of thermoplastic polymers using reactive solvents. High Performance Polymers, 8(1), 133-167. https://doi.org/10.1088/0954$0083 / 8 / 1 / 010$

DOI:

10.1088/0954-0083/8/1/010

Document status and date:

Published: 01/01/1996

\section{Document Version:}

Publisher's PDF, also known as Version of Record (includes final page, issue and volume numbers)

\section{Please check the document version of this publication:}

- A submitted manuscript is the version of the article upon submission and before peer-review. There can be important differences between the submitted version and the official published version of record. People interested in the research are advised to contact the author for the final version of the publication, or visit the $\mathrm{DOI}$ to the publisher's website.

- The final author version and the galley proof are versions of the publication after peer review.

- The final published version features the final layout of the paper including the volume, issue and page numbers.

Link to publication

\section{General rights}

Copyright and moral rights for the publications made accessible in the public portal are retained by the authors and/or other copyright owners and it is a condition of accessing publications that users recognise and abide by the legal requirements associated with these rights.

- Users may download and print one copy of any publication from the public portal for the purpose of private study or research.

- You may not further distribute the material or use it for any profit-making activity or commercial gain

- You may freely distribute the URL identifying the publication in the public portal.

If the publication is distributed under the terms of Article $25 f a$ of the Dutch Copyright Act, indicated by the "Taverne" license above, please follow below link for the End User Agreement:

www.tue.nl/taverne

Take down policy

If you believe that this document breaches copyright please contact us at:

openaccess@tue.nl

providing details and we will investigate your claim. 


\title{
Processing of thermoplastic polymers using reactive solvents
}

\author{
Han E H Meijer, Rob W Venderbosch, Johannes G P Goossens and \\ Piet J Lemstra \\ Centre for Polymers and Composites, Eindhoven University of Technology, PO Box 513, \\ $5600 \mathrm{MB}$ Eindhoven, The Netherlands \\ Received 4 October 1995, accepted for publication 15 December 1995
}

\begin{abstract}
The use of reactive solvents offers an interesting and flexible route to extend the processing characteristics of thermoplastic polymers beyond their existing limits. This holds for both intractable and tractable polymers. The first mainly applies for amorphous high- $T_{g}$ polymers where processing may be limited due to the high temperatures required which can cause problems related to degradation and where the solvent helps to decrease the processing temperature considerably. A prime example here can be found in the system poly(phenelyneether) PPE/epoxy. The second mainly holds for semicrystalline polymers and the attention here is focused on obtaining low viscosities in order to be able to apply alternative processing routes, like pouring or casting, for those polymers which are generally easy to process by more conventional techniques like injection moulding or extrusion. In this paper the model system poly(ethylene) $\mathrm{PE} /$ styrene is investigated. In both cases, based on intractable and tractable polymers, the solvent is polymerized after moulding, thus converting into a non-solvent, and becomes, after the concurrent phase separation and phase inversion, an integral and often structural part of the final product. Interestingly, specific morphologies, in terms of the size of the dispersed (previous solvent) phase formed or the position and thickness of in situ formed interlayers when polymerization occurs in the presence of a polar surface, can be obtained which can otherwise extremely difficult, or not at all, be realized. Moreover, flexibility of the choice of the reactive solvent creates tuneable mechanical (and, if requested, other) properties of those phases, varying from glassy, with a $T_{g}$ of typically $200^{\circ} \mathrm{C}$, to complete rubbery, with a $T_{g}$ far below room temperature. Of course a disadvantage of the technique is that a polymerization step must occur after the shaping process. Compared to more standard reactive processing techniques, however, clear advantages can exist with respect to the occurrence of early vitrification-yielding a fast demoulding possibility-induced by the reaction induced phase separation, and the fact that the continuous thermoplast phase ultimately determines the main product properties, including the possibility of second-stage deformability and reprocessability.
\end{abstract}

\section{Introduction}

In order to meet the ever-increasing demands put on polymeric materials in new applications, polymer chemists continue to synthesize new polymers that often can be regarded as intractable from a processing point of view. This is the case for either high-temperature polymers, developed for structural applications where a high glass transition temperature is required, or for polymers designed for those applications where a high molecular weight is necessary for mechanical reasons. Often the main advantage of polymers over the more traditional materials, which is their easy processability, is lost. In order to gain processability in practice compromises have to be accepted. Basically, one could state that most recent 
polymer development, as occurs in most of the large research laboratories of the main polymer producers all over the world and sometimes in the laboratories of important and big enough end-users, can be summarized as finding a continuous compromise to the stated controversy between introducing a low enough viscosity as required for easy processing while maintaining the most important part of the product's mechanical properties in terms of stiffness, strength and, especially, work-to-break (impact strength).

Traditionally, solutions are sought by tuning the molecular weight distribution, by introducing flexibility to the polymer backbone, thus lowering the $T_{g}$, or by blending the intractable polymers with more flexible polymers, for example in poly(phenylene-ether)poly(styrene) blends (Noryl from General Electric Plastics: PPE-PS). Alternatively, simple processing techniques with hardly any flow can be used combined with expensive postmachining, for example in products made from pressed and fused plates of ultra high molecular weight poly(ethylene) (UHMWPE), or processing aids like volatile solvents are applied, for example in spin coating processes or solution spinning operations for example of the same UHMWPE to produce high-performance fibres. The last compromises are restricted to products with a high surface to volume ratio, typically fibres and films, and violate the more modern environmental requirements and thus necessitate the need of complete solvent recovery. Moreover, the final product is only a (often relatively small) part of the main stream in the production process that almost exclusively consists of closed loop evaporation and condensation operations for the solvent. All those causes make the products of such a process necessarily expensive, but, more important, limit the use of those attractive polymers in many possible new applications. Also reactive processing techniques are used, as in prepreg fabrication, followed by hand lay-up or press operations, and filament winding techniques, as applied in composite manufacturing. Bulk moulding compounds (BMC) were developed that can be injection moulded, with or without the application of in-mould coatings. There are processes like casting and pouring of monomers or more elegant, automated processes like resin transfer moulding (RTM), and reinforced or structural reaction injection moulding (RRIM, SRIM). These techniques seemingly solve the stated contradiction, since monomers are generally present during processing which are converted into polymers only after their final shaping operation. Disadvantages and limitations exist, however. Apart from the introduction of chemistry to the end-user, which does not automatically guarantee the best control during polymerization, there is a need for almost complete conversion, since the product properties are directly and exclusively determined by the chemistry and only at the end of the polymerization are the mechanical properties obtained.

A possible solution to some of the problems mentioned is to process polymers with the use of reactive solvents. Basically the idea is to sell the solvent with and within the product after having it made harmless by applying a polymerization step. During processing, the solvent either allows a large reduction in the processing temperature (which is important for the intractable high-temperature polymers) or decreases the viscosity of the polymer such that standard (for intractable high molecular weight polymers), or (for tractable polymers) alternate, processing techniques, where a low viscosity is prerequisite, come within reach. After shaping, the solvent is converted into a non-solvent induced by the first polymerization step. Phase separation results, generally accompanied by phase inversion which happens to occur already when the volume fraction of the polymer exceeds about $10 \%$. A dispersed phase results, locking the original solvent inside the thermoplastic matrix material that forms the continuous phase. A schematic impression is depicted in figure 1 .

In this paper we will review several systems that can be regarded as some primary examples of how this processing technique could function. The first, and by far most 


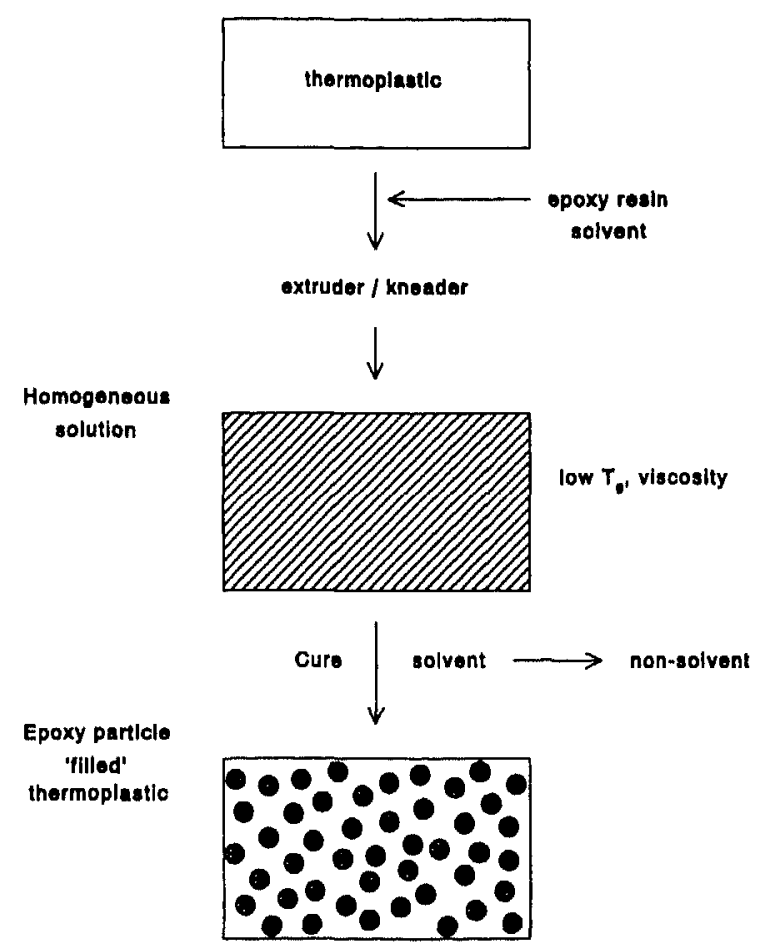

Figure 1. Schematic representation of the concept of processing of intractable polymers using reactive solvents.

extended part (Part I: intractable polymers), deals with the system PPE-epoxy [1-6]. After investigating the miscibility, the focus will be on the rheology, important during processing, and the morphology, which determines the final product properties. Different epoxies, aromatic versus aliphatic, are used to tune the properties of the dispersed phase. Accordingly, we will turn to composite applications where unique morphologies are obtained since the epoxy solvent during and/or after phase separation preferentially accumulates at the polar fibre surfaces. Possibly the optimal composite could be designed using this technique. In the second part (Part II: tractable polymers), the system poly(ethylene)-styrene (PE-St) [7], or alternatively poly(ethylene)-butylmethacrylate (PE-BMA) [8] will be presented. In this case, crystallization can interfere with the chemically induced phase separation and the focus will be on the morphology development during polymerization. The paper ends with some outlooks on possible applications in other fields, making use of the flexibility of this technique.

\section{PART I: INTRACTABLE POLYMERS}

\section{Miscibility, rheology and morphology}

\subsection{Materials choice: PPE-epoxy}

The materials used in this study were poly(2,6-dimethyl-1,4-phenylene ether) (PPE) as the thermoplast, an aromatic (stiff) epoxy, diglycidyl ether of bisphenol-A (DGEBA), 
an aliphatic (flexible) epoxy, diglycidyl ether of polypropylene oxide (DGEPPO) and the crosslinkers polypropylene oxide diamine (D-400) or the sterically hindered, and thus slow, 4,4'-methylene-bis(3-chloro-2,6-diethyl aniline) (M-CDEA) and 4,4'-methylenebis(2,6-diethyl aniline) (M-DEA) (see figure 2).

a)<smiles>CCOc1c(C)cc(C(C)C)cc1C</smiles>

b )<smiles>CC(C)(COc1ccc(C(C)(C)COc2ccc(C(C)(C)c3ccc(OCC(C)(C)c4ccc(OCC5CO5)cc4)cc3)cc2)cc1)c1ccc(OCC2CO2)cc1</smiles>

c)

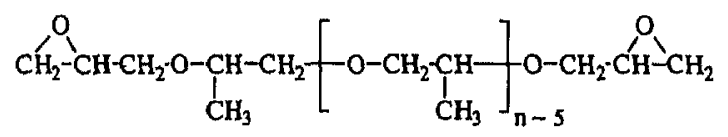

d)

$$
\underset{\mathrm{CH}_{3}}{\mathrm{H} \mathrm{N}-\mathrm{CH}-\mathrm{CH}_{2}}\left[\begin{array}{r}
\mathrm{O}-\mathrm{CH}_{2}-\mathrm{CH} \\
\mathrm{CH}_{3}
\end{array}\right]_{\mathrm{n} \sim \mathrm{S}}{ }_{\mathrm{NH}_{2}}
$$

e)

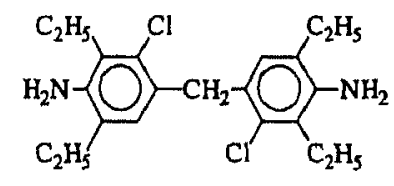

f)<smiles>CCc1cc(Cc2cc(CC)c(N)c(CC)c2)cc(C)c1N</smiles>

Figure 2. Structural formula of $(a)$ PPE, $(b)$ DGEBA, $(c)$ DGEPPO, $(d)$ Jeffamine D-400, (e) M-CDEA. (f) M-DEA.

Although epoxy resin proves to be a surprisingly effective solvent for many polymers, as can be concluded from a literature survey [9-53] (see table 1), PPE is chosen as a model polymer for its interesting mechanical properties in terms of a high glass transition 
temperature, $T_{g}$, a relatively high intrinsic impact strength and more or less standard values for modulus, yield stress and breaking strength. Given its high- $T_{g}$ of $220^{\circ} \mathrm{C}$, the processing temperature should be around $350^{\circ} \mathrm{C}$. This, in combination with the limited thermal and oxidative stability, results in severe degradation and, consequently, PPE can be considered as a classical example of an intriguing but intractable polymer.

Table 1. Overview of the epoxy/thermoplastic systems reported in literature [9-53].

\begin{tabular}{|c|c|c|c|}
\hline Polymer & Epoxy resin/curing agent & $\begin{array}{l}\text { Molecular weight } \\
\left(\mathrm{kg} \mathrm{mol}^{-1}\right)\end{array}$ & $\begin{array}{l}\text { Concentration } \\
(w t \%)\end{array}$ \\
\hline Poly(ethylene oxide) & $\begin{array}{l}\text { DGEBA [10] } \\
\text { DGEBA/TEPA [10] }\end{array}$ & $\begin{array}{l}20(n) \\
20(n)\end{array}$ & $\begin{array}{l}0-100 \\
0-90\end{array}$ \\
\hline Poly(methyl methacrylate) & $\begin{array}{l}\text { DGEBA [11] } \\
\text { DGEBA/3DCM [11] } \\
\text { DGEPPO/D230 [9] }\end{array}$ & $\begin{array}{l}28.3(n) / 60(w) \\
28.3(n) \\
200(w)\end{array}$ & $\begin{array}{l}0-100 \\
2-10 \\
90-100\end{array}$ \\
\hline Poly(styrene) & DGEPPO/D230 [9] & $200-400(w)$ & $50-100$ \\
\hline Poly(butylene terephthalate) & $\begin{array}{l}\text { DGEBA [12] } \\
\text { DGEBA/DDM [13] }\end{array}$ & $\begin{array}{l}37.8(v) \\
\mathrm{nr}\end{array}$ & $\begin{array}{l}0-10 \\
5-20\end{array}$ \\
\hline Poly(phenylene ether) & $\begin{array}{l}\text { DGEBA/PIP [14-16] } \\
\text { DGEBA/M-CDEA [17] } \\
\text { DGEPPO/M-CDEA [18] }\end{array}$ & $\begin{array}{l}34-42.5(w) \\
32(w) \\
32(w)\end{array}$ & $\begin{array}{l}<15 \\
15-100 \\
50-100\end{array}$ \\
\hline Poly(ether imide) & $\begin{array}{l}\text { TGDDM/DDS [19-25] } \\
\text { TGAP/DDS [26] }\end{array}$ & $\begin{array}{l}12-18(n) \\
18(n)\end{array}$ & $\begin{array}{l}0-30 \\
0-40\end{array}$ \\
\hline Poly(imide) & TGDDM/DDS [27] & $10(n), 26(w)$ & $0-10$ \\
\hline Poly(carbonate) & DGEBA/CTBN/DDM [28] & $16(v)$ & $0-20$ \\
\hline Phenolphthalein poly(ether ether sulphone) & $\begin{array}{l}\text { DGEBA [29] } \\
\text { DGEBA/DDM/DDS/MA/PA [29] }\end{array}$ & $\begin{array}{l}\mathrm{nr} \\
\mathrm{nr}\end{array}$ & $\begin{array}{l}0-100 \\
0-20\end{array}$ \\
\hline Poly( $\epsilon$-caprolactone) & $\begin{array}{l}\text { DGEBA/DGEBF/PGEPF }[30,31] \\
\text { DDM/NMA/TETA }\end{array}$ & $20(v)$ & $0-25$ \\
\hline Poly( $p$-phenylene terephthalamide) & DGEBA/DDM [32] & $\mathrm{nr}$ & $0-10$ \\
\hline Poly(ether sulphone)s & $\begin{array}{l}\text { TGDDM/DGEBA/TGAP [33-45] } \\
\text { DDS/DDM/PA/Dicy }\end{array}$ & $\begin{array}{l}85(w)-145(w) \\
85(w)-145(w)\end{array}$ & $\begin{array}{l}0-60 \\
0-60\end{array}$ \\
\hline Poly(aryl ether sulphone)s & DGEBA/DDS/PIP [46-51] & $3(n)-15(n)$ & $0-25$ \\
\hline Poly(aryl ether ketone)s & DGEBA/DGR/DDS/DDM $[52,53]$ & $3(n)-7(n)$ & $0-40$ \\
\hline
\end{tabular}

nr: no value reported, $n, w, v$ : number, weight or viscosity average molecular weight.

DGEBA: diglycidyl ether of bisphenol-A; DGEBF: diglycidyl ether of bisphenol-F; TGDDM: $N, N, N^{\prime}, N^{\prime}$. tetraglycidyl 4,4'diaminodiphenylmethane; TGAP: triglycidyl $p$-aminophenol; DGR: diglycidyl ether of resorcinol; PGEPF: polyglycidyl ether of phenol formaldehyde novalac; DGEPPO: diglycidyl ether of poly(propylene oxide); DDM: 4,4' diaminodiphenylmethane; DDS: $4,4^{\prime}$ diaminodiphenylsulphone; M-CDEA: 4,4' methylene-bis(3-chloro2,6-diethylaniline); PIP: piperidine; Dicy: dicyandiamide; 3DCM: 4,4'-diamino-3,3'-dimethyldicyclohexylmethane; TEPA: tetraethylenepentamine; MA: maleic anhydride; PA: phthalic anhydride; Jeffamine D230: polypropylene oxide diamine; NMA: 'Nadic' methyl anhydride; TETA: triethylenetetramine. 


\subsection{Thermally induced phase separation (TIPS)}

The miscibility of PPE-DGEBA was measured by light scattering $(632 \mathrm{~nm})$. The cloud point curve, which indicates the onset of phase separation, was recorded upon slowly cooling $\left(1^{\circ} \mathrm{C} \mathrm{min}^{-1}\right)$ solutions of different compositions, contained between two glass covers. Below $30 \mathrm{wt} \%$ epoxy the glass transition temperature was measured by using dynamic mechanical thermal analysis (DMTA) at $1 \mathrm{~Hz}$ in tensile mode during heating at $3{ }^{\circ} \mathrm{C} \mathrm{min}^{-1}$. The resulting phase diagram is given in figure 3 , from which it can be concluded that rather high temperatures are required to obtain homogeneous solutions. This figure combines the data of light scattering with those obtained via rheological measurements (see section 1.4).

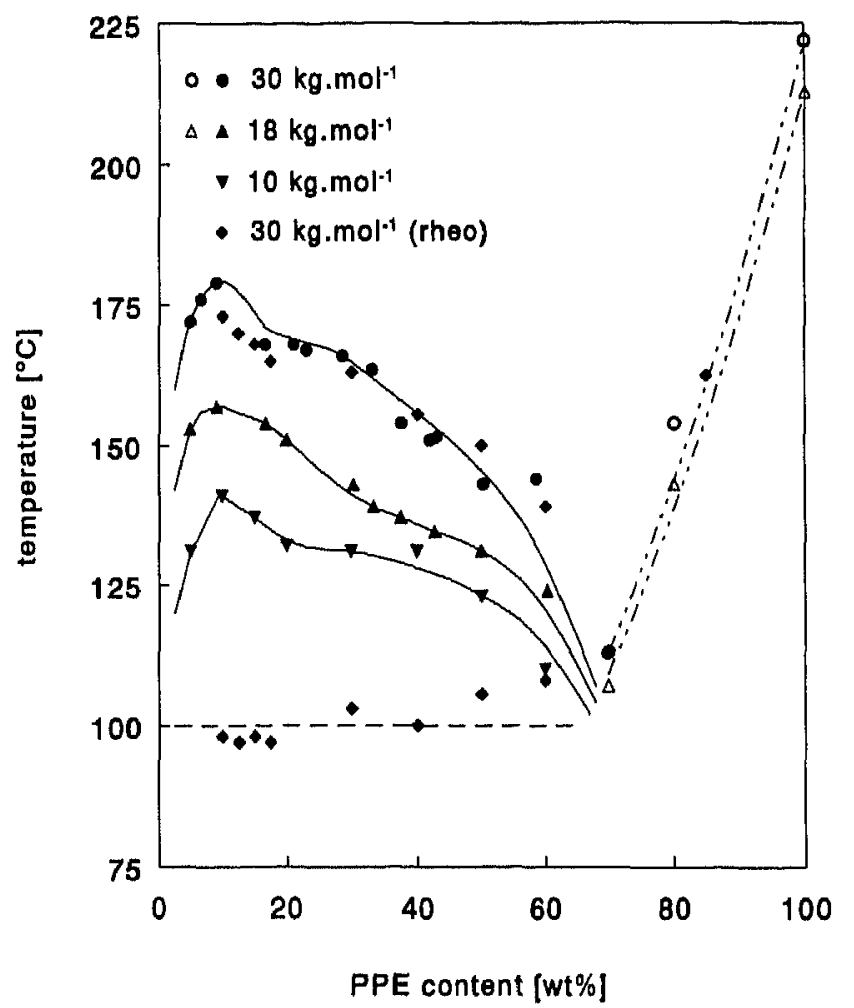

Figure 3. Phase diagram of PPE/epoxy solutions as derived from light scattering experiments $(\bullet, \Lambda, \nabla)$, DMTA $(O, \Delta)$ and rheology $(\downarrow),(-)$ onset phase separation; ( - - -) $T_{g}$-composition line of heterogeneous solutions; $(-\ldots-) T_{g}$-composition line of homogeneous solutions.

The cloud point curves exhibit a typical upper critical solution temperature (UCST) behaviour, commonly observed for polymer-solvent systems. As expected, a decrease in the PPE molecular weight enhances the miscibility of the system and results in a considerable shift of the cloud point curve to lower temperatures. Since PPE as well as the epoxy resin are polydisperse, the cloud point curves may not be regarded as binodal curves and do not give any information about the composition of the coexisting phases. The inflection in the curves clearly reveals the influence of the molecular weight distribution, i.e. the critical point is not situated at the top of the curves. The $T_{g}$-composition lines, as determined by DMTA and as calculated with the Fox equation [54] (using a $T_{8}$ of 222 and $213^{\circ} \mathrm{C}$ for 


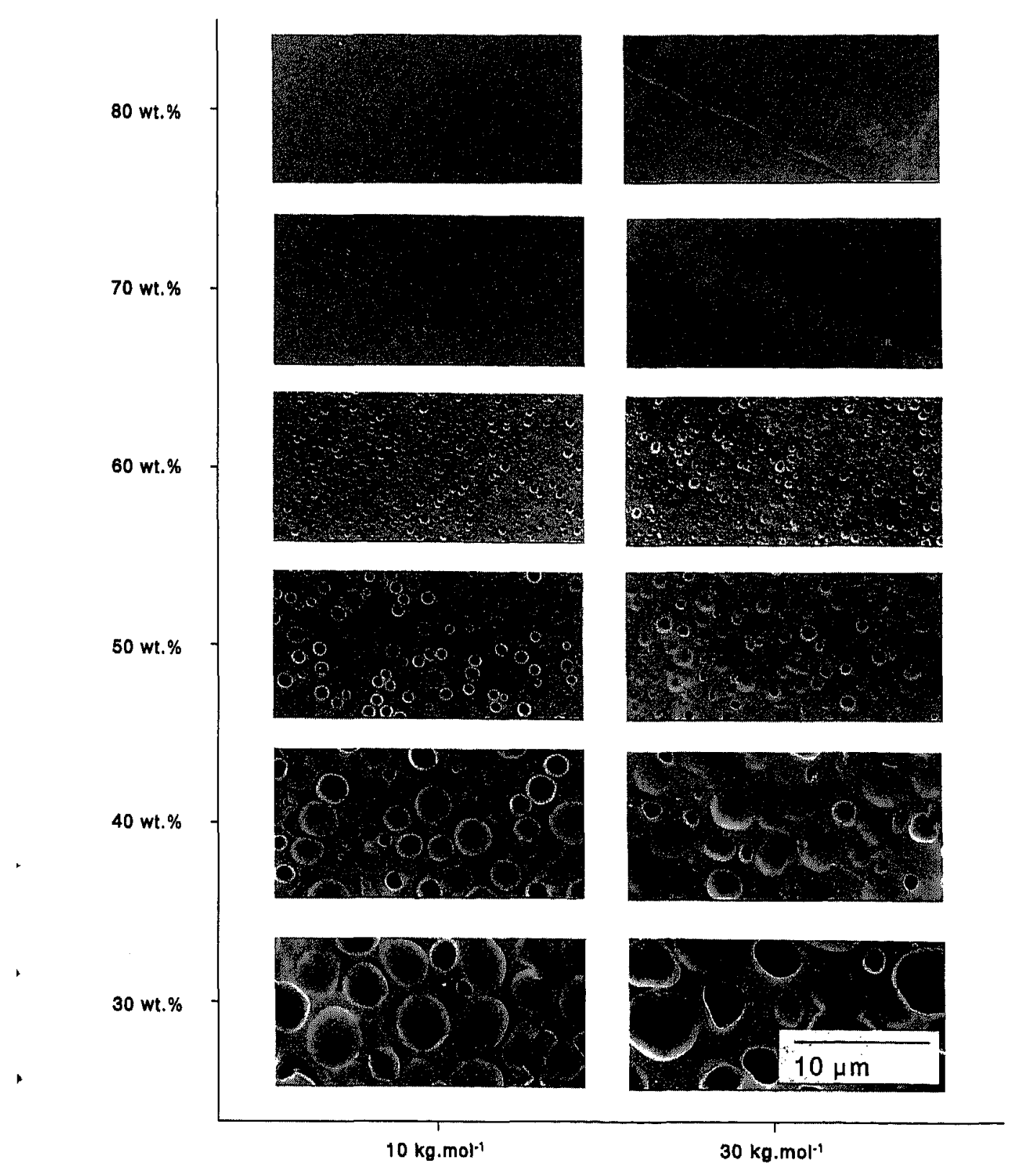

Figure 4. Scanning electron micrographs of PPE/epoxy solutions with a PPE molecular weight of 10 and $30 \mathrm{~kg} \mathrm{~mol}^{-1}$ and a PPE content of $30-80 \mathrm{wt} \%$, after cooling from $200^{\circ} \mathrm{C}$ to room temperature at a rate of $1{ }^{\circ} \mathrm{C} \mathrm{min}^{-1}$.

PPE with a molecular weight of 30 and $18 \mathrm{~kg} \mathrm{~mol}^{-1}$ respectively and a $T_{g}$ of $-18^{\circ} \mathrm{C}$ for the epoxy monomer), are also plotted in the same figure and they intersect the cloud point curves at a PPE content of $\sim 70 \mathrm{wt} \%$. Thus, solutions with less than $70 \mathrm{wt} \%$ PPE phase separate upon cooling; however, phase separation is not complete, but arrested as soon as the PPE-rich phase vitrifies at this intersection point (the so-called Berghmans point $[55,56]$ ). 


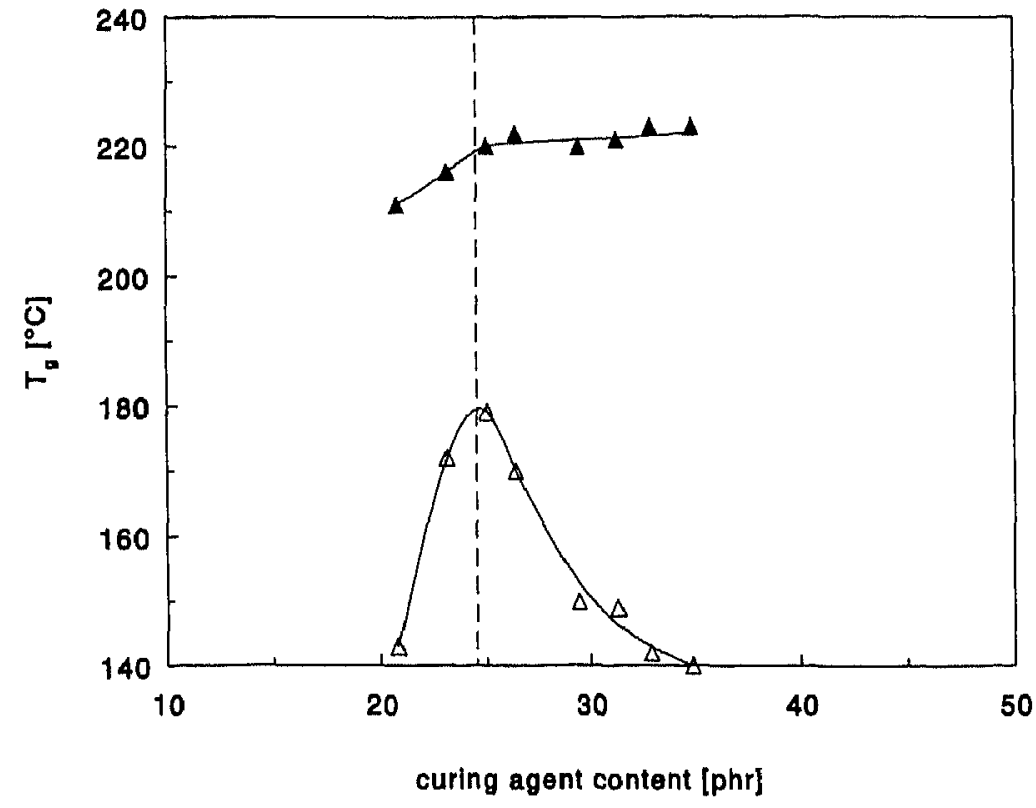

Figure 5. Glass transition temperature versus curing agent concentration of the epoxy $(\Delta)$ and PPE phase ( $\Lambda$ ), as determined using DMTA (frequency $1 \mathrm{~Hz}$ ) for cured blends containing $35 w t \%$ epoxy $\left(30 \mathrm{~kg} \mathrm{~mol}^{-1}\right)$ (the broken line indicates the stoichiometric concentration).

As a result of this phenomenon, which physically can be regarded as a thermoreversible gelation, all the phase separated solutions exhibit a $T_{g}$ of $\sim 100^{\circ} \mathrm{C}$, as indicated by the broken horizontal line in figure 3 . This typically TIPS (thermally induced phase separation) behaviour is in essential contrast to the CIPS (chemically induced phase separation) process, which is the genuine topic of this paper. In the latter case complete phase separation can be accomplished as will be shown below. The morphologies resulting from the TIPS process are shown in figure 4 and reveal a phase-inverted morphology, with a dispersed epoxy phase in a continuous PPE phase, for all PPE fractions investigated (i.e. $\geqslant 30 \mathrm{wt} \%$ ). In accordance with the phase diagram of figure 3 , a homogeneously vitrified material is found above 70 wt\% PPE. The size of the dispersed phase is relatively uniform and depends on the PPE fraction, apparently due to retardation of the coarsening process by the presence of a more viscous matrix.

\subsection{Chemically induced phase separation (CIPS)}

In solutions with reactive solvents, the main driving force for phase separation is the increase in the molecular weight of the solvent via a step polymerization mechanism. As shown by Verchère and co-workers [57-61] and De Graaf [62], for epoxy systems toughened with (in order to prevent phase inversion) relatively small volume fractions of carboxyl-terminated butadiene-acrylonitrile copolymer (CTBN rubber) and poly(ether sulphone) (PES), respectively, a minor increase in the molecular weight of the solvent significally reduces the miscibility of the system and phase separation is initiated at relatively low conversions. CIPS can be regarded as inducing a shift, and concurrent change in shape, of the cloud point curves in the phase diagram (see figure 3) towards higher temperatures 

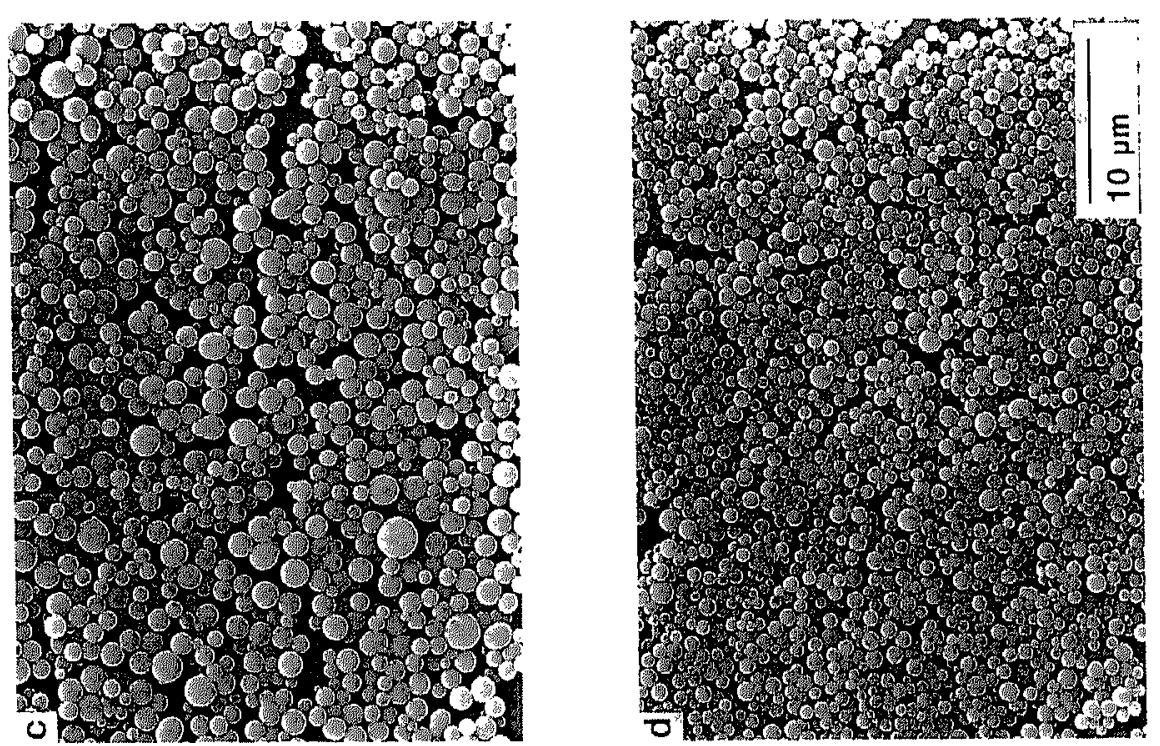

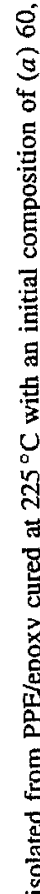
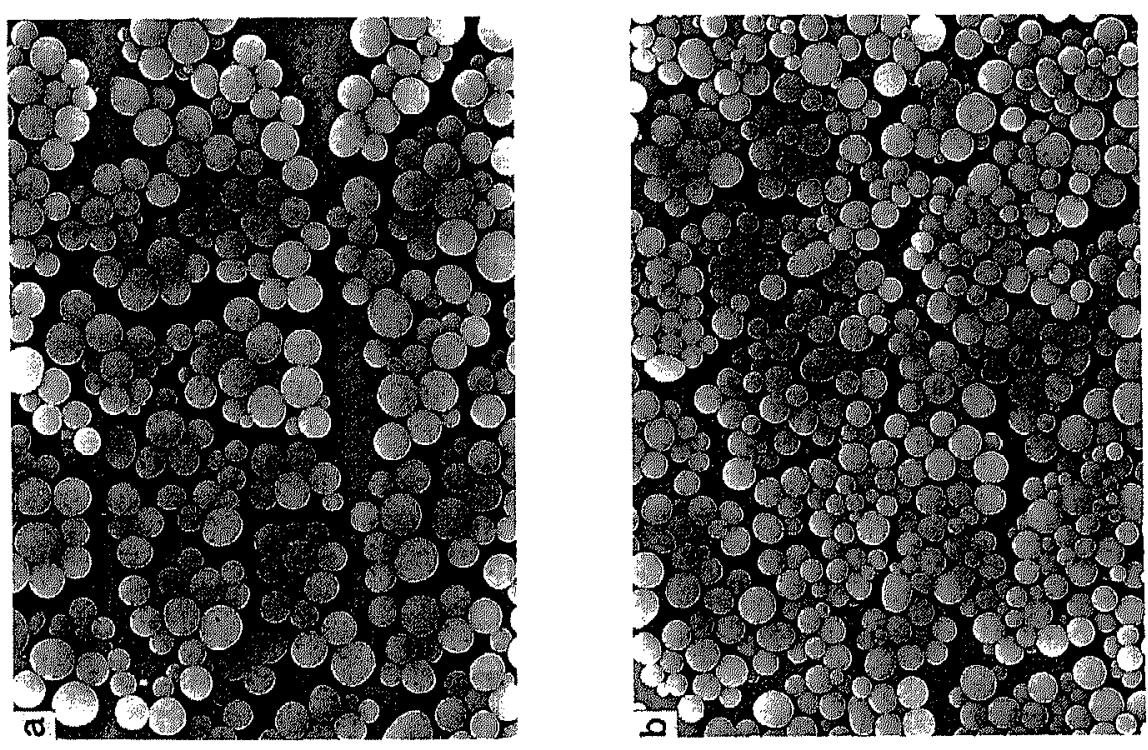

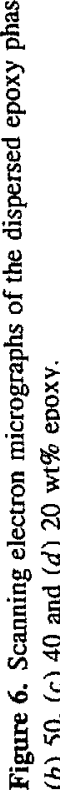




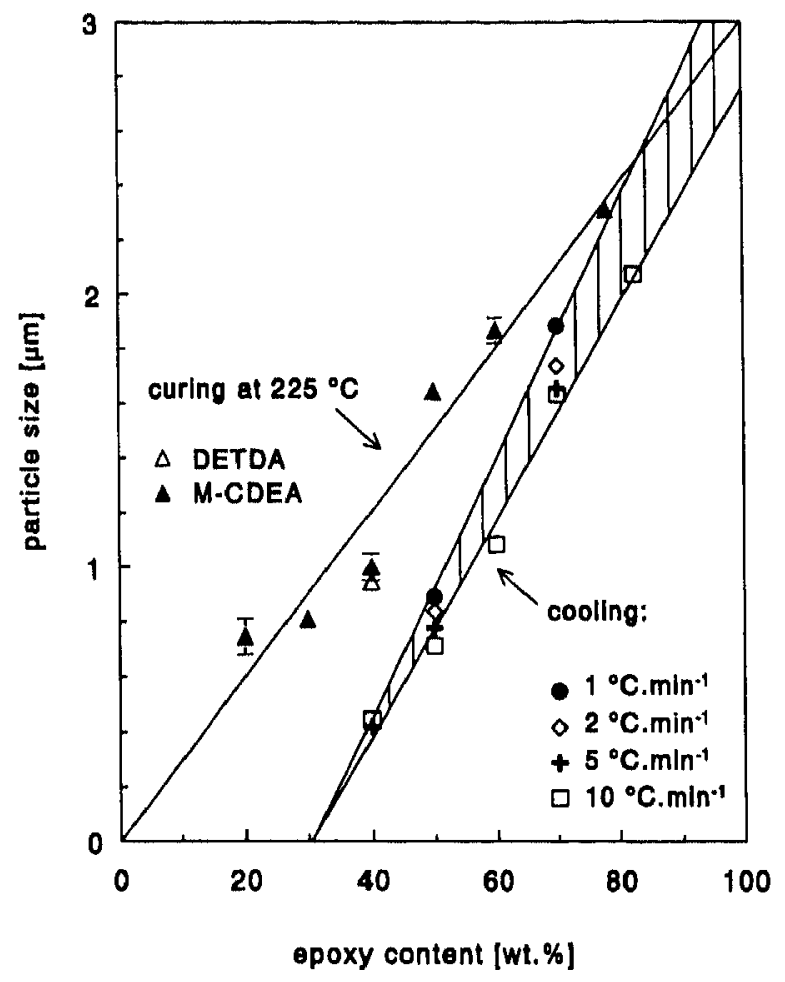

Figure 7. Number-average particle size of PPE/epoxy systems; as a function of composition after isothermal curing with M-CDEA $(\Lambda)$ and diethyltoluenedi-amine: DETDA $(\Delta)$ at $225^{\circ} \mathrm{C}$ or after cooling from the homogeneous region to room temperature at a rate of $1,2,5$ and $10^{\circ} \mathrm{C}$.

and, comparing the process to the more familiar TIPS, it is sometimes referred to as a 'chemical quench', which is confusing. Of course the tendency of coarsening [6367], eventually resulting in two fully separated layers as in TIPS, exists, but now it is counteracted by a number of processes. The coarseness of the final morphology is controlled by the competition of the rates of phase separation and coalescence (i.e. diffusion-Ostwald ripening - and hydrodynamically driven break-up and coalescence processes) on one hand and the rates of vitrification and gelation on the other hand.

The required compatibility or the curing agents with the PPE/epoxy solutions makes it difficult to estimate their appropriate concentration. For aromatic diamines, the concentration should be equal to the stoichiometric ratio, but an excess is likely to be required in order to compensate for any loss of curing agent due to dissolution in the PPE phase after phase separation. For this reason the optimal concentration, defined as the concentration which results in the highest $T_{g}$ of the epoxy phase, was determined using DMTA. Figure 5 shows the results. First, it is recognized, as already anticipated above, that with CIPS higher $T_{g}$ values of the PPE are obtained compared with the maximum value $\left(T_{g} \sim 100^{\circ} \mathrm{C}\right.$, see figure 3) resulting from TIPS, indicating that now complete phase separation is indeed obtained, at least for polymerization temperatures $\geqslant T_{g, \max }$. This is of utmost importance, not only for the expected mechanical properties, but also for the non-toxicity of the final product. The latter is clearly illustrated by the optimal concentration of (generally toxic) 

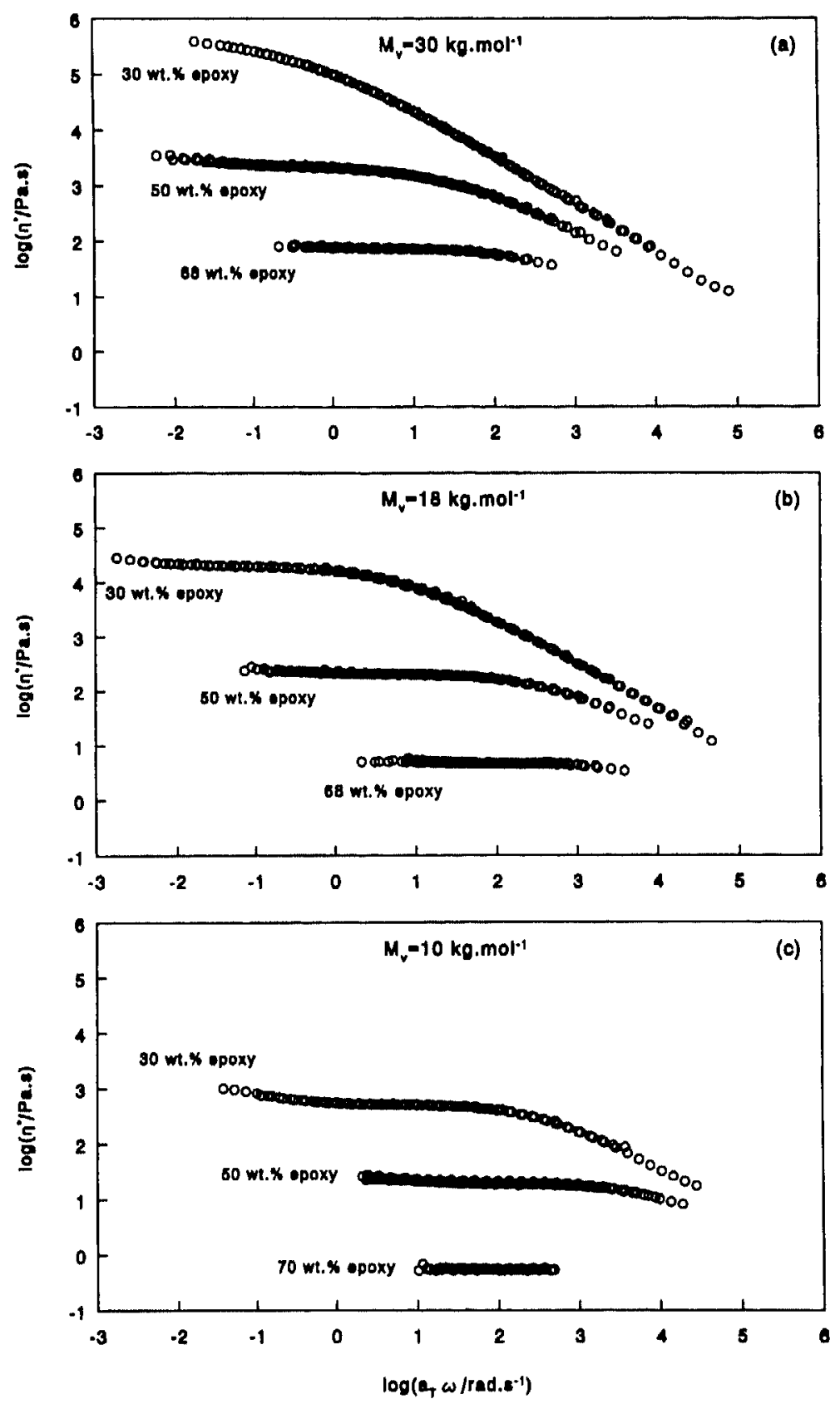

Figure 8. Dynamic viscosity versus reduced frequency of PPE/epoxy solutions with epoxy contents of 30,50 and $70 \mathrm{wt} \%$ and for PPE molecular weights of (a) $30 \mathrm{~kg} \mathrm{~mol}^{-1}$. (b) $18 \mathrm{~kg} \mathrm{~mol}^{-1},\left(\right.$ c) $10 \mathrm{~kg} \mathrm{~mol}^{-1}$ (reference temperature is $170^{\circ} \mathrm{C}$ ).

curing agent that proves to be very close to, or even at, the stoichiometric ratio, as revealed by the pronounced maximum in the epoxy $T_{g}$. This can be explained by the fact that both 


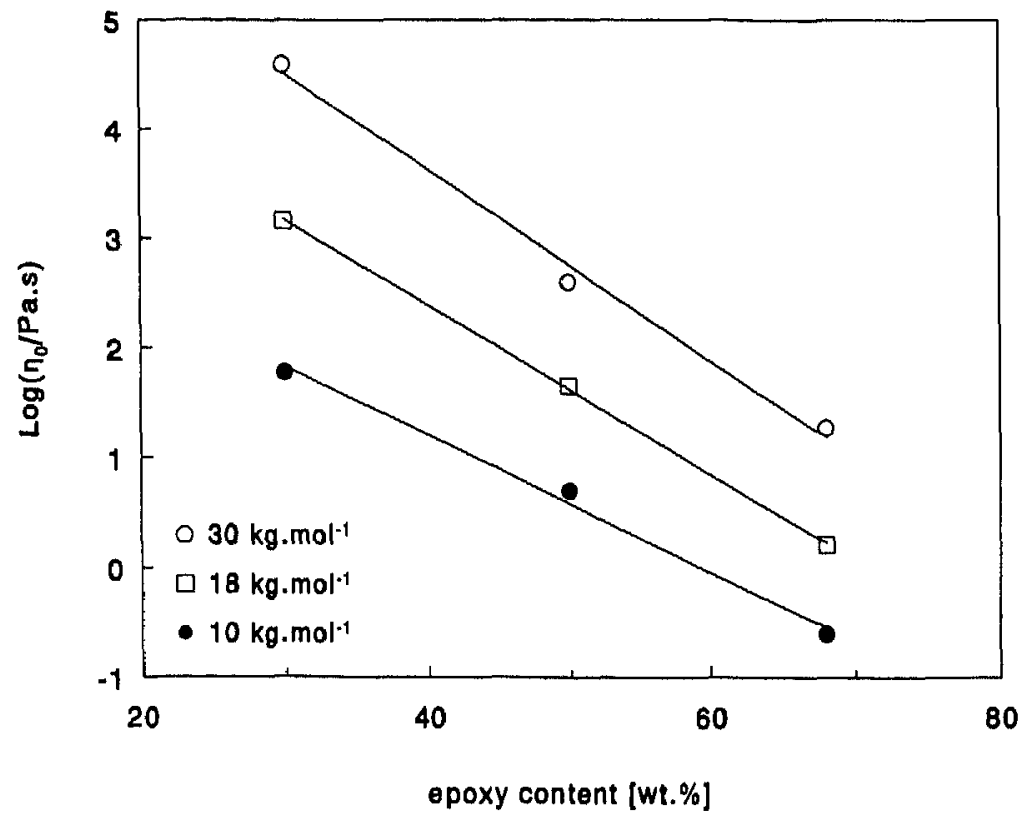

Figure 9. Zero-shear viscosities of PPE/epoxy solutions as a function of PPE molecular weight and epoxy content (reference temperature is $200^{\circ} \mathrm{C}$ ).

a deficiency (resulting in incomplete curing) as well as an excess (yielding a more linear polymerization) result in a lower $T_{8}$.

The morphology of the cured samples is given in figure 6, for four weight fractions in the relevant mid-region, prepared by extraction of part of the (thermoplastic PPE) matrix. Relatively monodispersed epoxy spheres with a particle size distribution of $D_{w} / D_{n} \sim 1.2$ are found.

Comparison of the resulting average particle sizes from the TIPS and CIPS processes reveals a remarkable resemblance in their dependence of the viscosity of the matrix during phase separation, as reflected in the strong dependence on the epoxy content (see figure 7). A clear difference exists, however, in their limits towards high fractions of PPE: 0\% for CIPS, showing complete phase separation in this case, versus $30 \%$ for TIPS, which is again the Berghmans point where the PPE-rich phase vitrifies. No distinct influence of the cooling rate nor the curing temperature was observed for this system. This is not a general rule, however, since for some other polymer-reactive solvent systems [68], recently under investigation in our laboratory, a distinct dependence on curing temperature and curing rate is sometimes found. This effect becomes even more important for semicrystalline polymers, where locking-in by crystallization, that can interfere with phase separation, is possible (see Part II).

\subsection{Rheology and chemorheology}

The dynamical rheological behaviour of the homogeneous solutions was studied by using a Rheometrics RDS-II spectrometer with a parallel plate set-up and a frequency range of $0.05-200 \mathrm{rad} \mathrm{s}^{-1}$, at different temperatures. Depending on the viscosity of the solution, a plate diameter of 8,25 or $50 \mathrm{~mm}$, a gap distance of 0.5 to $2 \mathrm{~mm}$, and a maximum 

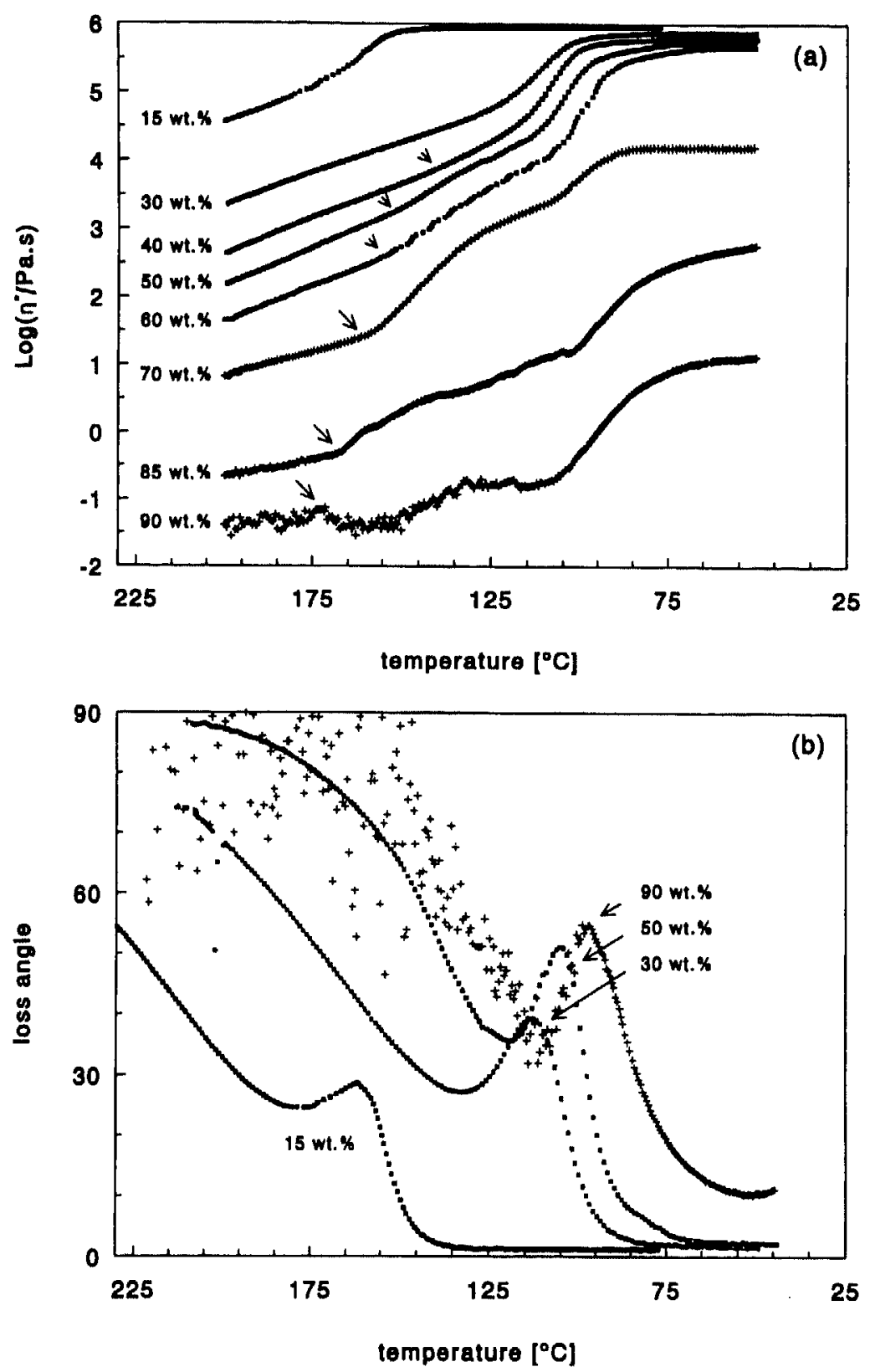

Figure 10. Rheology of PPE/epoxy solutions upon cooling from the homogeneous region to room temperature at a rate of $5{ }^{\circ} \mathrm{C} \mathrm{min}-1$ (parameter is the epoxy concentration in the solutions): (a) dynamic viscosity, (b) loss angle (strain $<3 \%$, frequency $=10 \mathrm{rad} \mathrm{s}^{-1}$, plate diameters of $50 \mathrm{~mm}(+)$ and $25 \mathrm{~mm}([\mathrm{D}))$. (The arrows indicate the onset of phase separation.)

strain of $3 \%$, was applied. Finally, the complete curves were constructed by shifting the measured curves to a reference temperature of $170^{\circ} \mathrm{C}$, according to the time-temperature superposition principle. The results in figure 8 show typical shear thinning behaviour which 

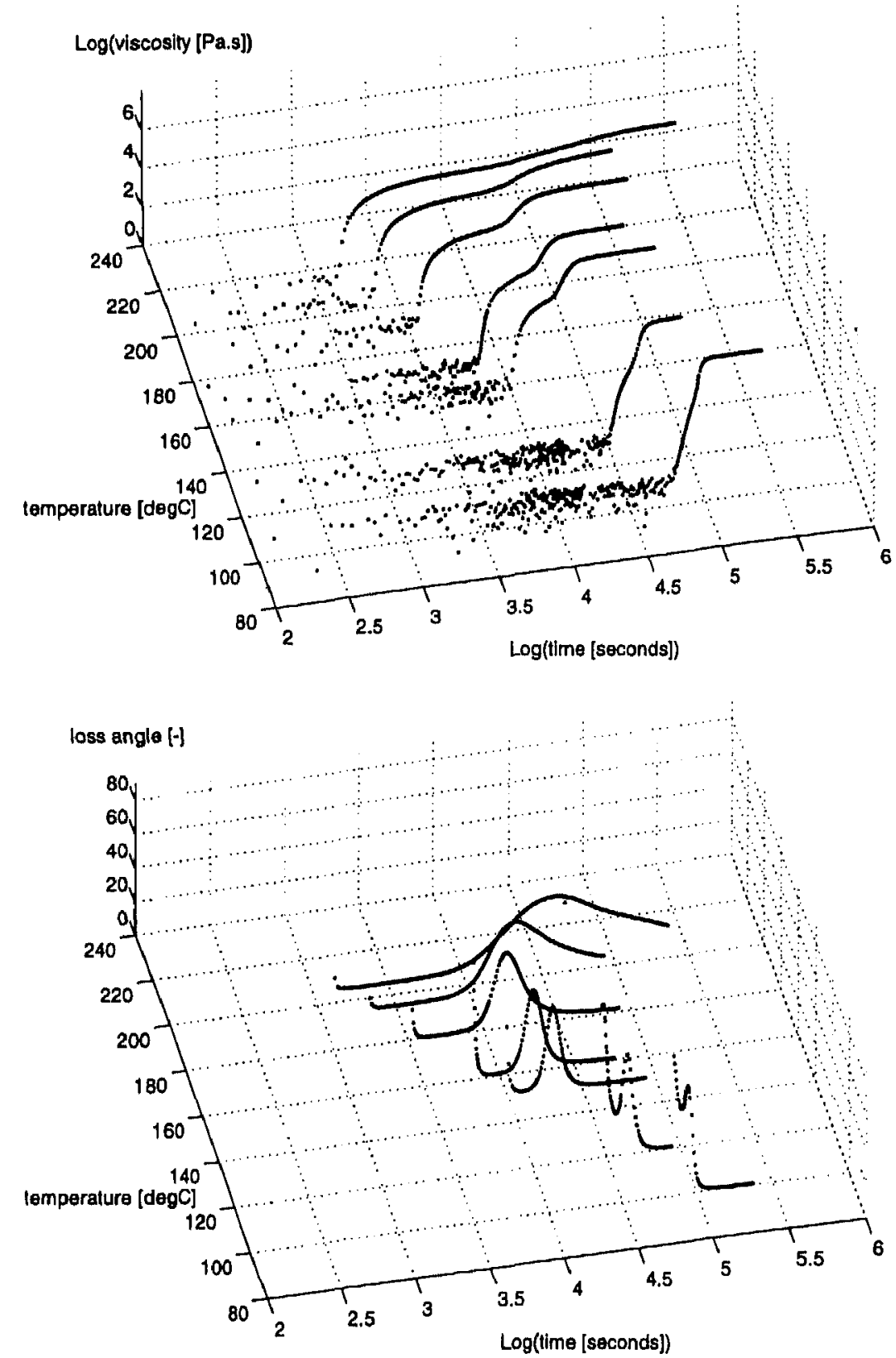

Figure 11. Rheology upon isothermal curing of epoxy/M-CDEA (52 phr): top, dynamic viscasity; bottom, loss angle (strain $<2 \%$, frequency $=10 \mathrm{rad} \mathrm{s}^{-1}$, plate diameter of $8 \mathrm{~mm}$ ).

is commonly observed for semidilute solutions. The expected strong dependence on both the volume fraction and molecular weight of the PPE is confirmed. Moderately high zero shear viscosities are found (see figure 9) which are comparable to those of standard thermoplastic polymers. They demonstrate the success of the original objective for intractable polymers, 


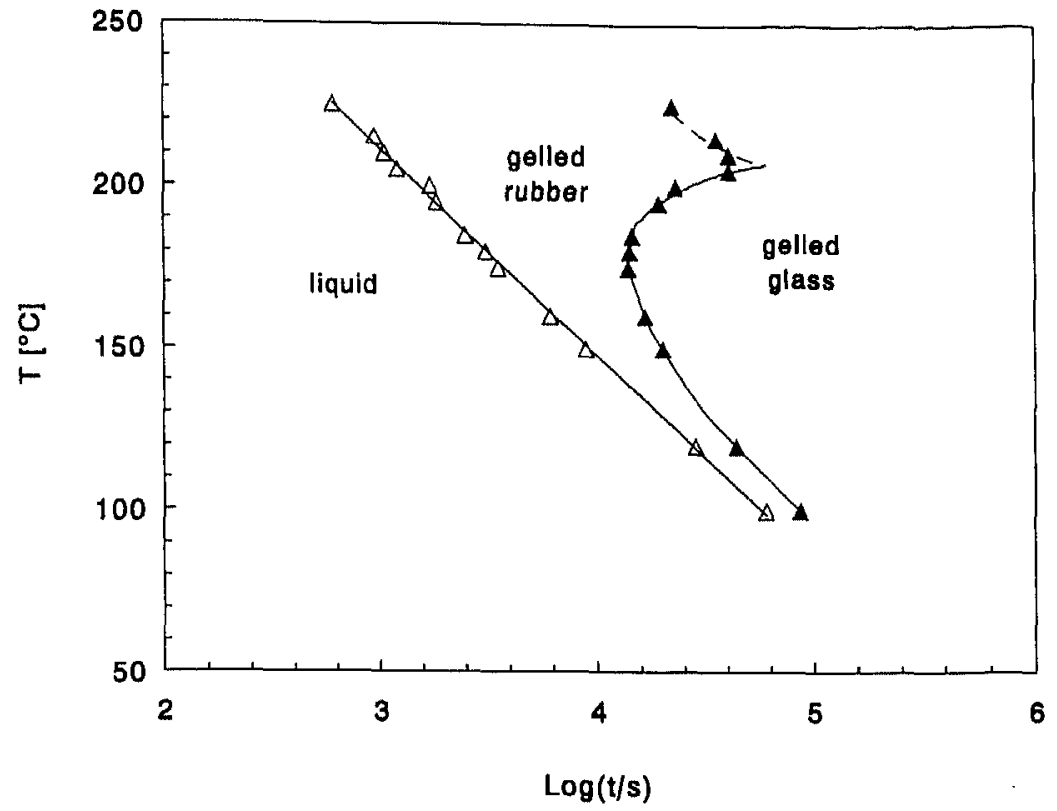

Figure 12. The time-temperature-transformation diagram of epoxy/M-CDEA presenting the times to gelation $(\Delta)$ and the times to vitrification $(\Delta)$ upon isothermal curing.

which was lowering the processing temperature (to 170 and $200^{\circ} \mathrm{C}$ in figures 8 and 9 respectively) rather than decreasing the viscosity.

In order to study the morphology development in more detail, three different rheological experiments were performed: (i) solutions without curing agent (PPE-epoxy) were analysed upon cooling at $5^{\circ} \mathrm{C} \mathrm{min}^{-1}$; (ii) using $\mathrm{M}-\mathrm{CDEA}$ as a curing agent, the isothermal curing of epoxy was studied (epoxy-M-CDEA) in a temperature range of $100-225^{\circ} \mathrm{C}$; and (iii) the chemorheology of the complete system (PPE-epoxy-M-CDEA) was investigated.

(i) PPE-epoxy. The dynamic viscosity and loss angle of different PPE-epoxy solutions as a function of temperature, obtained via slow cooling at $5^{\circ} \mathrm{C} \mathrm{min}^{-1}$, are plotted in figure 10 . Structure development upon cooling is recognized via the onset of phase separation (arrows) followed by the evolution (increase in viscosity due to the formation of a continuous PPErich phase) and, finally, vitrification. At high PPE concentrations, it is increasingly difficult to detect the onset of phase separation, due to reduction in its rate and its effect on viscosity. Only in the very dilute regions ( $\geqslant 90 \mathrm{wt} \%$ epoxy), is a decrease in viscosity found, indicative of a continuous epoxy phase accompanied by a dispersed PPE phase. The vitrification of PPE can still be recognized in the distinct peak in the loss angle, which may be caused by the formation of an interconnected structure. Interestingly, the phase diagram can be derived from these experiments as well, as was already depicted in figure 3 . The difference with the light scattering technique is that now also the $T_{g}$ of the phase-separated systems can be measured directly as well as the vitrification using only a single technique.

(ii) Epoxy-M-CDEA. Due to the large viscosity differences that occur upon the isothermal curing of epoxy, it is difficult to monitor its value using only one parallel plate set-up and other techniques, like torsional braid analysis (TBA) [69], are usually applied. However, since we are mainly interested in measuring the time to gelation and vitrification, and not so much in the exact value of the viscosity in the low range, we decided to install 

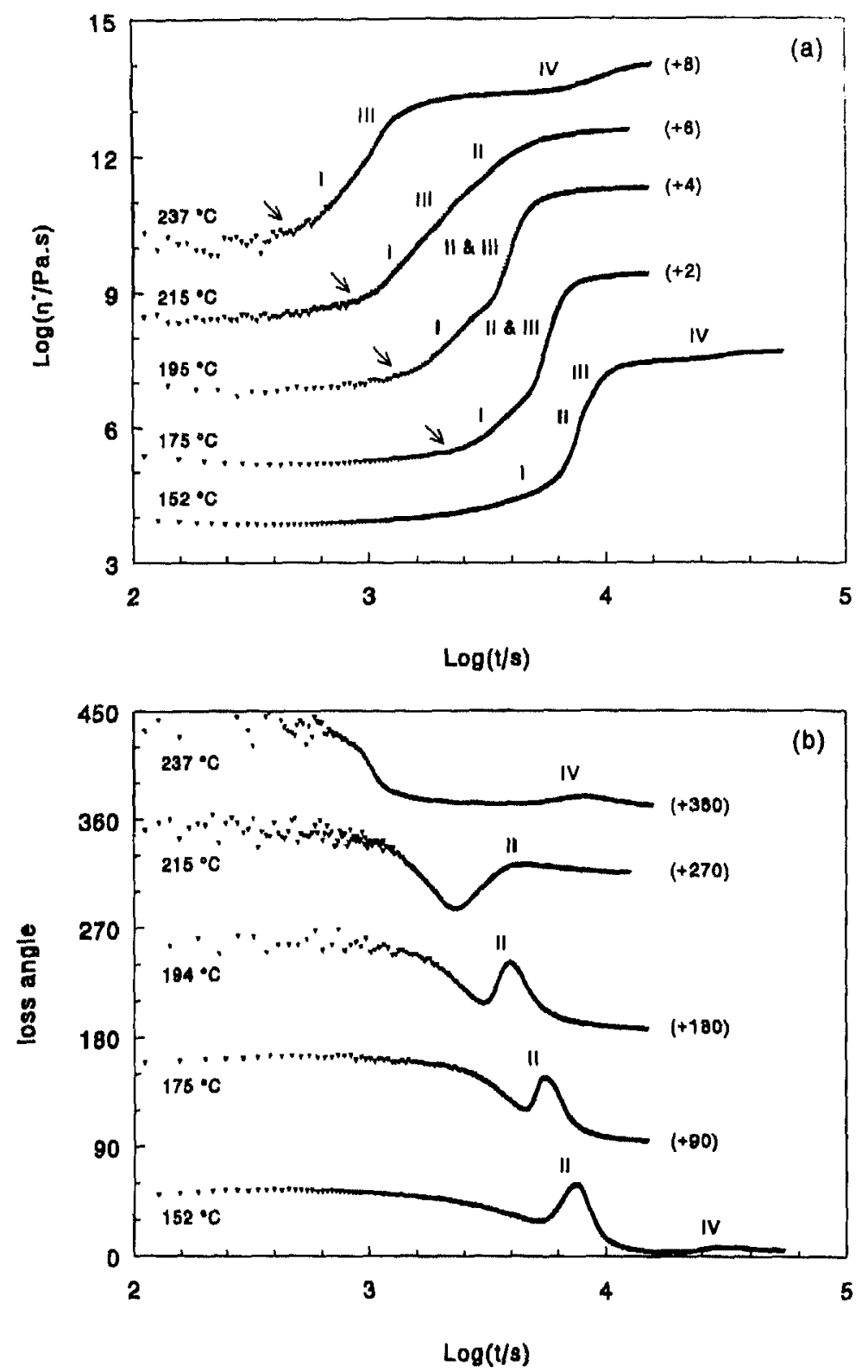

Figure 13. $(a),(b)$ : Rheology upon isothermal curing of PPE/epoxy (50 wt\% epoxy) versus temperature: $(a)$ dynamic viscosity, $(b)$ loss angle (strain $<2 \%$, frequency $=10 \mathrm{rad} \mathrm{s}^{-1}$, plate diameter of $8 \mathrm{~mm}$ ) (the arrows indicate the onset phase separation). (For clarity the curves are shifted upwards by the values indicated in parentheses.) $(c),(d)$ : Rheology upon isothermal curing of PPE/epoxy at $200^{\circ} \mathrm{C}$ versus composition: (c) dynamic viscosity, $(b)$ loss angle (strain $<2 \%$, frequency $=10 \mathrm{rad} \mathrm{s}^{-1}$, plots are a combination of measurements with a plate diameter of $50(-)$ and $8 \mathrm{~mm}(+)$, except for the system with $39 \mathrm{wt} \%$ epoxy) (the drawn curve in (c) is obtained on a Brookfield rheometer). (For clarity the curves are shifted by the values in parentheses.) $t_{\text {gel }}$ and $t_{\text {vir }}$ of epoxy/M-CDEA are given as references. 

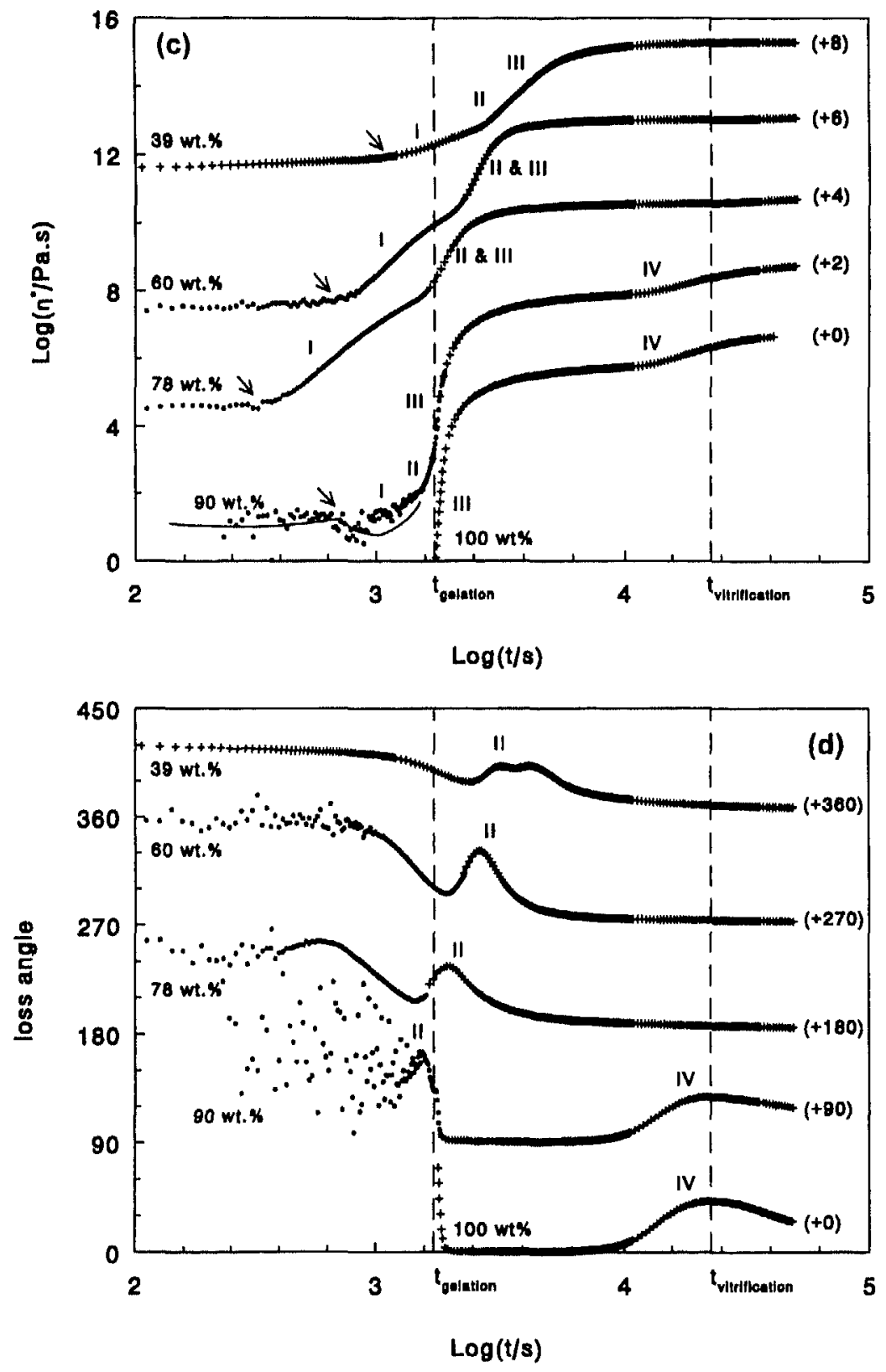

Figure 13. (Continued)

the smallest available plate, $8 \mathrm{~mm}$, accepting some scatter in the initial experimental data. The results of the curing at different temperatures are plotted in figure 11, showing a distinct jump in viscosity at the gel point and a maximum in the loss angle at vitrification.

All these data can be combined in a so-called TTT diagram (time, temperature, transformation) as extensively treated by Gillham and co-workers [69]. This diagram is valid for isothermal curing only and, consequently, may be read in the horizontal direction 
only (figure 12).

Gelation occurs, independently of the curing temperature, at a constant conversion (for this system at about $58 \%$ ). Consequently, an exponential reduction in time-to-gelation is found with increasing temperature. In contrast, the time to vitrification reveals a distinct minimum at about $180^{\circ} \mathrm{C}$, due to the competing effects with increasing curing temperature of the reaction rate on the one hand and the conversion required for vitrification on the other hand. The deflection to shorter times at temperatures higher than $200^{\circ} \mathrm{C}$, could be due to homopolymerization or degradation of the epoxy.

(iii) PPE-epoxy-M-CDEA. Now the total system can be analysed. All experimental results are summarized in figure 13 , showing the dynamic viscosity and loss angle versus time with the polymerization temperature (figures $13(a)$ and $(b)$ ) and the composition (figures $13(c)$ and $(d)$ ) as a parameter. Again, first the onset of phase separation (arrows) and the gradual increase in viscosity due to the formation of a PPE-rich continuous phase is recognized (I). Accordingly, vitrification of this phase (II) and gelation of the dispersed epoxy phase (III) is found, although mostly I and II are difficult to distinguish since they happen almost simultaneously, followed by the vitrification of the epoxy phase (IV). At low temperatures, vitrification of PPE occurs before gelation of the epoxy phase and no interference of the gelation on the final morphology can be expected, while at high temperatures this could be the case-although only in the case of reaction rates much faster than the phase separation rate can a pronounced influence be anticipated. In the slow curing system with M-CDEA, as used in this study, this is not the case and the morphology basically depends uniquely on the phase-volume ratio at the moment of phase separation.

The composition data in figures $13(c)$ and $(d)$ clearly reveal a minimum time for phase separation to occur at $78 \mathrm{wt} \%$ epoxy, in accordance with UCST behaviour and the phase inversion is detected to occur between 90 and $78 \mathrm{wt} \%$ epoxy, accompanied by a large rise in viscosity yielding early matrix vitrification (most pronounced at intermediate polymer concentrations between 78 and $60 \mathrm{wt} \%$ epoxy), yielding possibilities for early demoulding.

In conclusion, rheological measurements prove to be a useful tool in monitoring the morphology development upon isothermal curing of PPE-epoxy-M-CDEA. In this system, the morphology is mainly controlled by the formation of a highly viscous PPErich continuous phase at the early stages of the reaction-induced phase separation process. Only at polymerization rates considerably higher than the rate of phase separation is a pronounced influence on the final morphology anticipated.

\section{Mechanical properties}

\subsection{The epoxy phase}

In order to systematically vary the mechanical properties of the dispersed phase, two basic routes are available: varying (i) the crosslink density [70-75] or (ii) the flexibility 76] of the epoxy network. The first can be realized by using resins with a higher starting molecular weight; however, this will strongly reduce the solubility of the PPE. Alternatively, an excess in curing agent or the use of bifunctional curing agents could be sonsidered, since both methods yield a more linear polymerization, but these techniques how a high sensitivity towards the stoichiometry and problems with the reproducibility tre to be expected. Moreover, by only changing the crosslink density, a limited range in roperties is to be expected. Therefore, only the second route is explored here and flexibility was introduced by applying different combinations of aromatic and aliphatic epoxies (see igure 2) DGEBA/DGEPPO: $110 / 0,80 / 20,60 / 40,40 / 60,20 / 80$ and 0/100 with M-CDEA 
or D-400 (see [3] for more details). Figure 14 shows that the glass transition temperature of the resulting epoxy material gradually decreases from $200^{\circ} \mathrm{C}$ to $-30^{\circ} \mathrm{C}$, as a unique function of the total polypropylene oxide content.
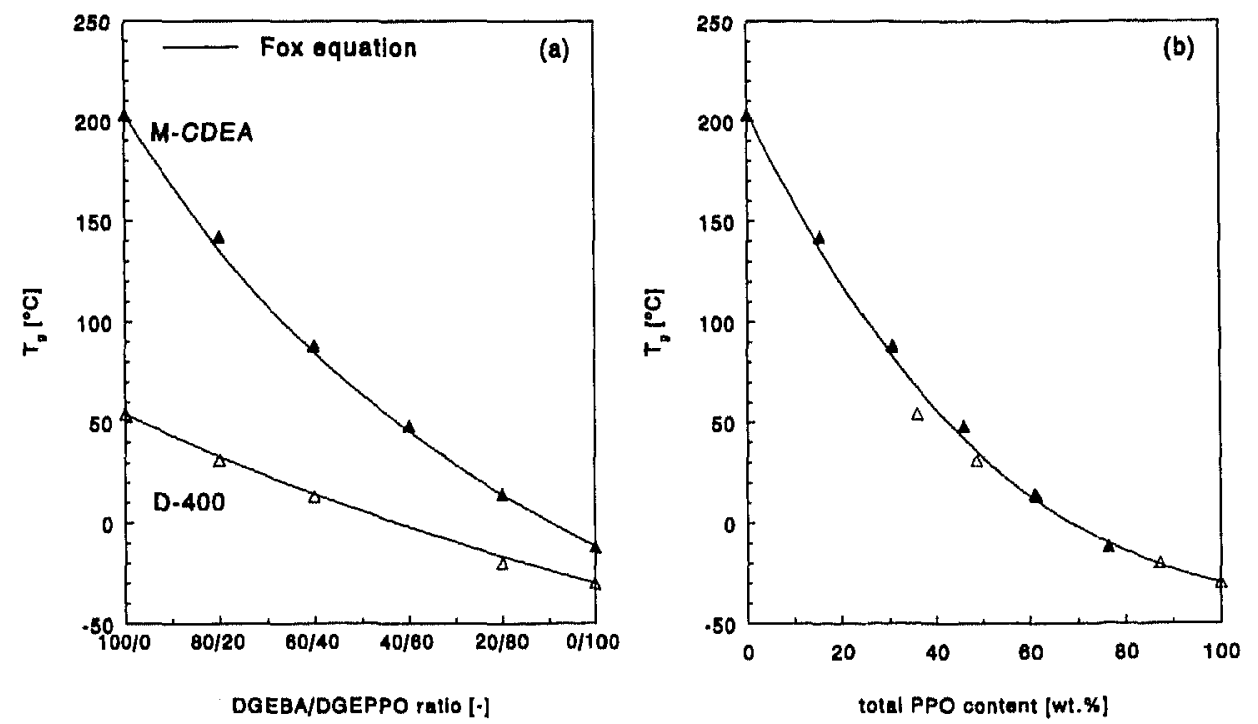

Figure 14. Glass transition temperatures, as determined using DMTA $\left(2{ }^{\circ} \mathrm{C} \min ^{-1}, 1 \mathrm{~Hz}\right)$, of mixtures of DGEBA and DGEPPO resin cured using M-CDEA $(\Delta)$ or Jeffamine D-400 $(\Delta)$ versus (a) DGEBA/DGEPPO ratio (drawn curves are according to the equation of Fox), (b) total polypropylene oxide (PPO) content.

The Young's modulus, strength and strain-to-break are given in figure 15 and reveal the great flexibility in tuning the properties of the epoxy phase, from a brittle glass to a ductile, but relatively brittle, rubber, depending on the position of $T_{g}$ relative to room temperature.

\subsection{The total PPE/epoxy system}

Of course it is intriguing to investigate what will be the influence of the above demonstrated drastic change in mechanical properties of the dispersed phase when we use the different epoxy systems as reactive solvents for PPE. The miscibility of PPE-DGEPPO proved to be slightly decreased relatively to PPE-DGEBA; only a very small shift of the cloud point curve towards higher temperatures resulted. The morphology of the cured systems proved to be very similar to what we already found: micrometre sized droplets of epoxy in a continuous PPE phase. The main mechanical properties of the total system are summarized in figure 16, showing the modulus, yield stress and (high-speed) fracture toughness values as a function of the amount of epoxy added with the ratio DGEBA/DGEPPO as a parameter.

Indeed properties can be tuned but, more interestingly, the reactive solvent, after being used as a processing aid, is locked-up as an integral part of the resulting product inside the thermoplastic matrix and can form a useful and structural element, as is clearly illustrated by the considerable toughness enhancement obtained when rubbery epoxies are used (see figure $16(c)$ ). 


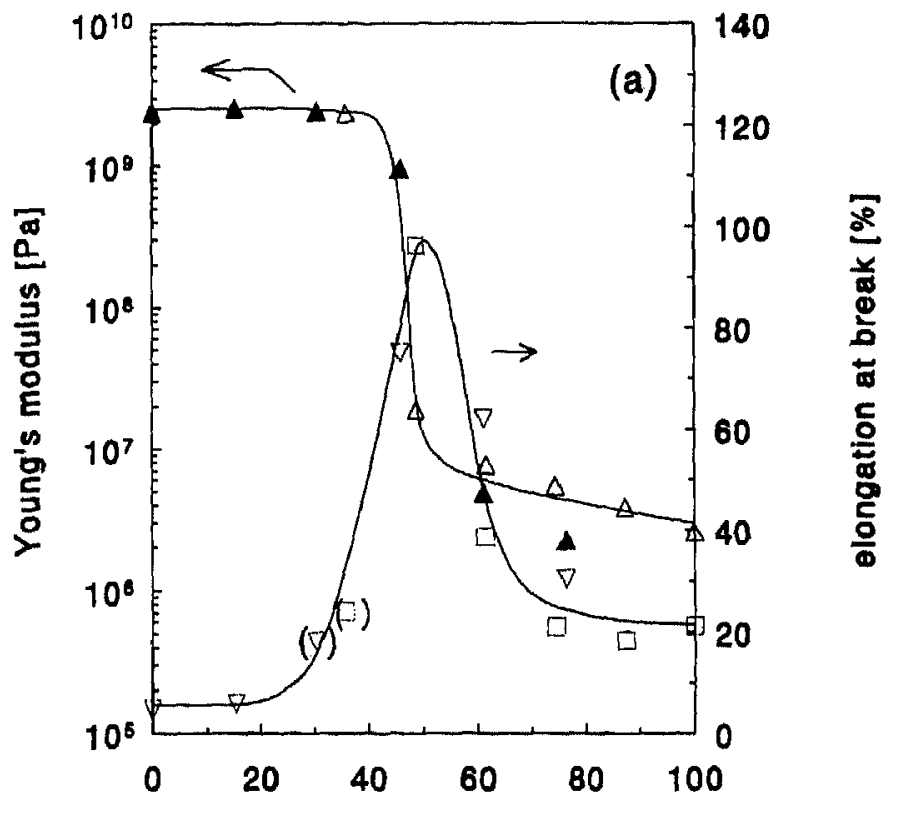

total PPO content [wt.\%]

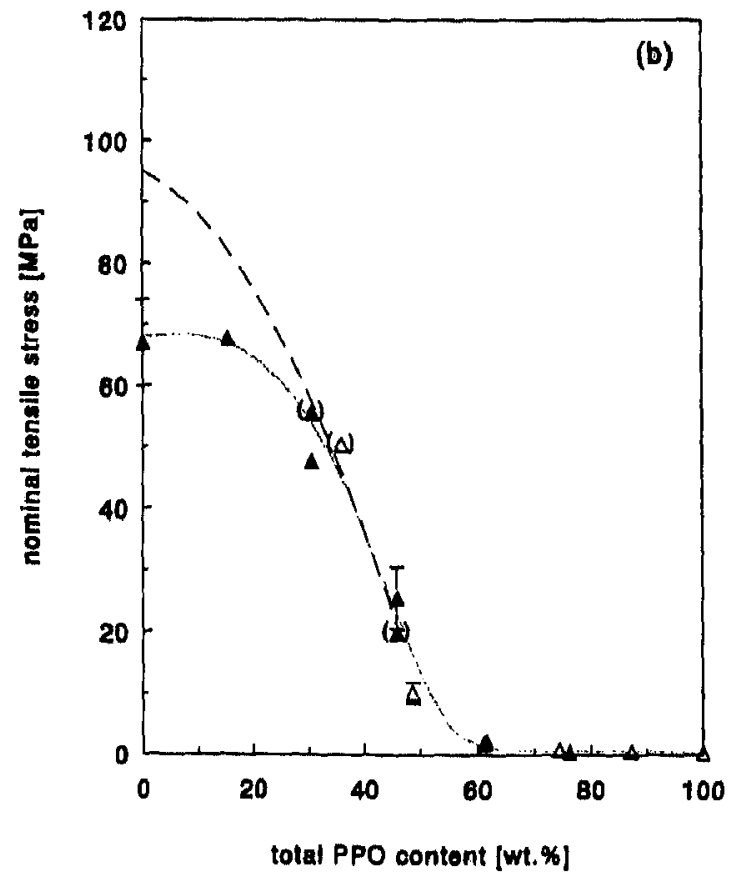

Figure 15. Tensile properties of the epoxy resin system, cured with M-CDEA (A) or Jeffamine D-400 $(\Delta)$, versus the total PPO content: $(a)$ Young's modulus and elongation at break (values given in parentheses are estimated from neck geometry), (b) stress at break (if observed, additionally the yield stress is presented by the markers in parentheses). 

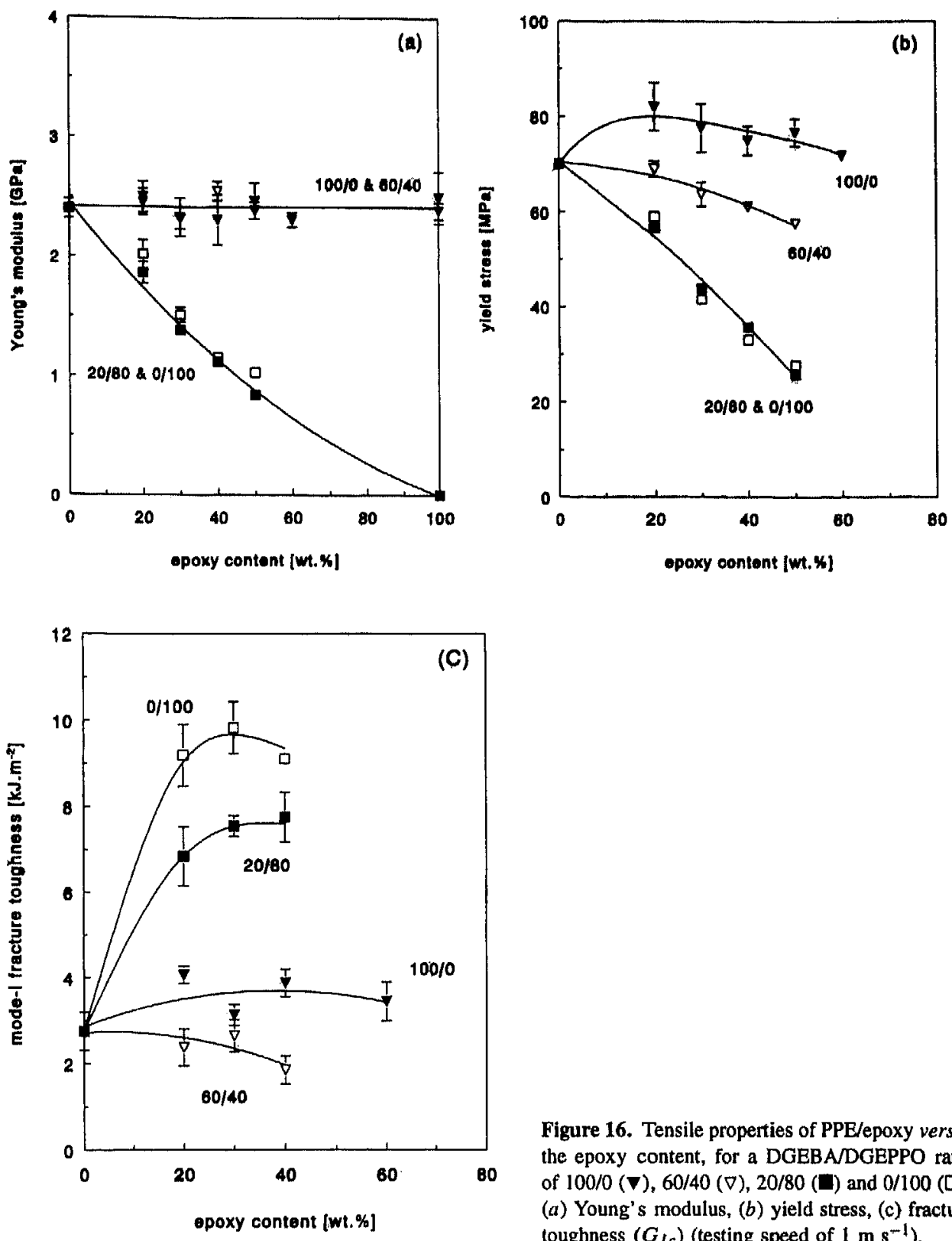

Figure 16. Tensile properties of PPE/epoxy versus the epoxy content, for a DGBBANDGEPPO ratio of 100/0 ( $), 60 / 40(\nabla), 20 / 80(\mathbb{D})$ and $0 / 100(\square)$ : (a) Young's modulus, (b) yield stress, (c) fracture toughness $\left(G_{l c}\right)$ (testing speed of $1 \mathrm{~m} \mathrm{~s}^{-1}$ ).

\section{Composite applications}

Making use of these newly developed polymer systems, high- $T_{g}$ thermoplastic composites were prepared using film stacking technology. By introducing epoxy resin as a reactive solvent, the flow was apparently sufficiently increased to fully wet and impregnate the fibres yielding composite materials of high quality (see figure 17).

Microscopic analysis of the matrix material revealed an interesting structure, i.e. the epoxy phase tends to accumulate at polar surfaces such as those of glass and carbon fibres 


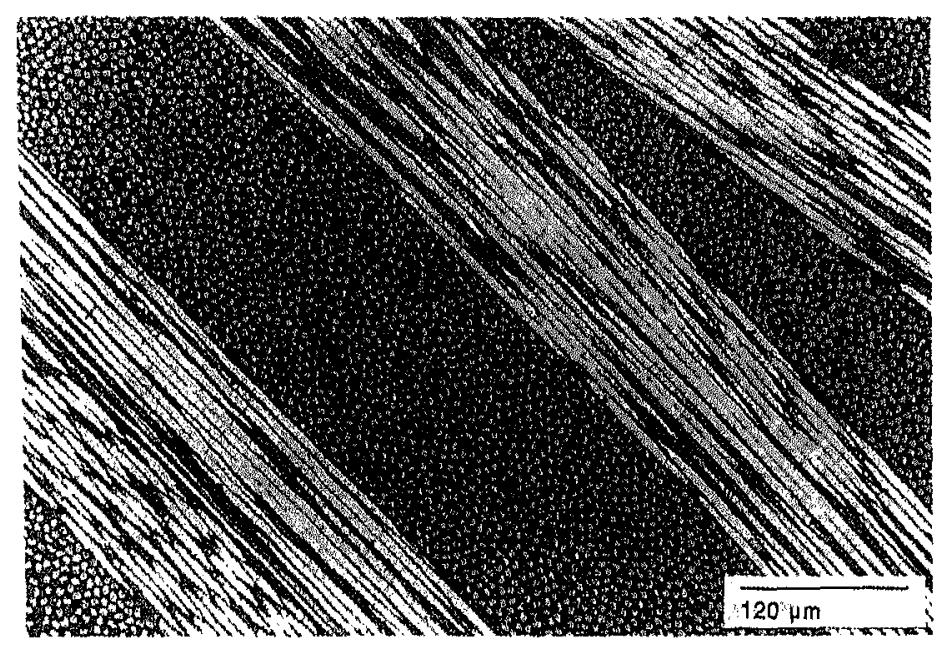

Figure 17. Optical micrograph of a polished cross section of PPE/epoxy-based (40 wt $\%$ epoxy, $55 \mathrm{phr}$ M-CDEA) carbon-fabric-reinforced composite (50 vol.\% fibres).

(see figure 18). Remarkably, this phase segregation is nearly complete in the case of high fibre loadings and, for a fibre volume fraction of $50 \%$, a morphology of epoxy-coated fibres in a pure PPE matrix is found (see figure 19).

This (unique) morphology is not only of great importance with respect to the possibility of drastically improving the strength of the interface or the level of adhesion between fibres and matrix, but also offers the potential to individually coat fibres with a thick and tunable (e.g. glassy or completely rubbery) interphase. The prerequisite for complete phase separation to occur is that, apart from the apparent influence of the fibre volume fraction or fibre spacing, sufficient mobility and time is available to complete this diffusion controlled process. For the fixed reaction rate of the system employed in this study, the viscosity of the matrix plays a dominant role, as is clearly illustrated in figure 20 .

This figure reveals that only when more than $30 \mathrm{wt} \%$ epoxy is present is complete phase separation to the surface achieved and a nearly neat PPE matrix, without inclusions of remaining epoxy spheres, results. This is confirmed by transverse flexural strength tests on unidirectional composites that show that the maximum properties are obtained as soon as a continuous epoxy interphase is formed (see figure 21).

From all properties measured (with typical values for flexural moduli of $40 \mathrm{GPa}$ and strength values of $0.7 \mathrm{GPa}$, for this high- $T_{g}\left(220^{\circ} \mathrm{C}\right)$, thermoplastic, $50 \%$ carbon fabric reinforced, composite) the impact properties proved to be most interesting, as shown in the mode I and II critical strain energy release rate [77], given in figure 22, and in the C-scan results after impact (see figure 23).

The synergy found in the mode-II results can be explained by an apparent optimal combination of brittle and ductile matrix components. The brittle epoxy phase enclosing all fibres not only yields a strong and good adhering interface, but also induces an increase of the deformation area ahead of the crack, and consequently the level of toughness, assuming that cracks in the epoxy coating can initiate yielding in the adjacent PPE matrix. Since mode-II results of interlaminar fracture toughness tests relate linearly [78-81] to the values of the practical (Boeing) compressive strength after impact (CSAI), these results are of great practical importance. Possibly by introducing these brittle interphases, a method may be 

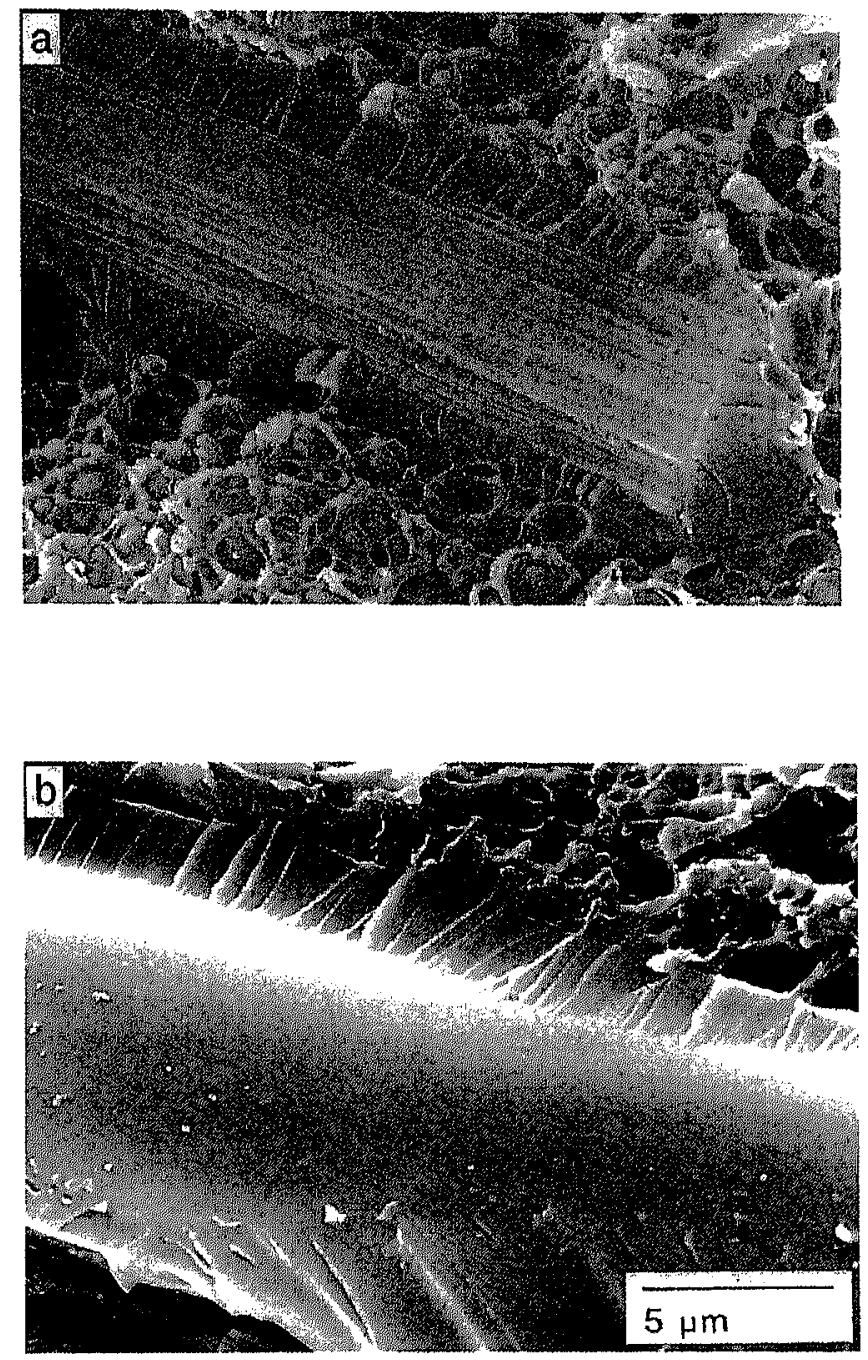

Figure 18. SEM micrographs of fracture surfaces of short-fibre-reinforced composites ( 17 vol.\% fibres) based on PPE/epoxy (56 wt\% epoxy, 25 phr Ethacure 100): (a) Grafil X-AS carbon fibre, (b) E-glass fibre.

found to toughen fibre-reinforced composites with a ductile thermoplastic matrix, beyond the usual limits imposed by the presence of the rigid fibres.

The macroscopic properties of the composites are strongly influenced by changing the properties of the interphases from glassy to rubbery, by replacing DGEBA by DGEPPO. Glassy interphases were shown to be in favour of structual applications, while rubbery interphases are preferred in structures requiring a high energy absorption potential. A detailed discussion of these experiments is, however, beyond the scope of this paper.

By changing the viscosity and the chemistry of the systems employed, for example by using end-modified, low molecular weight PPEs that can co-react with the reactive solvent, the currently existing limits with respect to the diffusion-controlled complete phase 


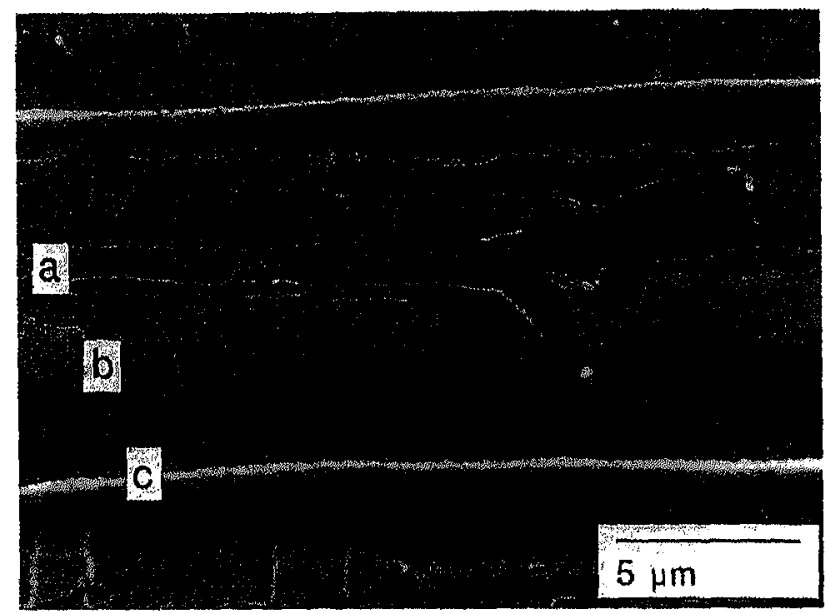

Figure 19. SEM micrograph of fracture surface in fibre-rich area of PPE/epoxy-based (40 wt\% epoxy, 55 phr M-CDEA) carbon-fabric-reinforced composite (50 vol.\% fibre): (a) fibre (imprint), (b) epoxy layer, (c) PPE matrix.

separation could be surpassed and thinner interphases could be realized. Other possibilities for further optimization, that should be based on micromechanical analyses as demonstrated by de Kok et al [82], can subsequently be explored.

\section{PART II: TRACTABLE POLYMERS}

\section{Miscibility and morphology development}

\subsection{Materials choice}

In the processing of tractable polymers with the aid of reactive solvents, we do not aim so much at decreasing the processing temperature. Nevertheless, to be able to process tractable polymers like polyamines, polyesters or polyolefines, like poly(ethylene) (PE), poly(propylene) (PP) and their copolymer rubbers (EPR) including ethylene-propylenediene terpolymers (EPDM), at low temperatures could find interesting applications. In contrast, here we focus on decreasing the viscosity during processing (e.g. injection moulding of extremely easy flowing $\mathrm{PP}$-grades, easy impregnatable thermoplastic grades of PP, PET or PBT for composite applications) or we aim at both effects combined (e.g. the development of EPDMs pourable at room temperature). Moreover, tractable polymers could possibly surpass one of the severe limits put on this new development so far (apart from the area of thermoplastic composites that can be easily thermoformed in a second step), i.e. the need for reactive processing routes at the end-user. In that case we should focus the research on obtaining unique, but stable, morphologies via the use of reactive diluents, made via reactive compounding or bulk polymerization of an intermediate product that can be ground or granulated and reprocessed in a subsequent shaping step. Basically, we seek alternative routes for realizing special morphologies like in high-impact poly(styrene) (PS), acrylonitrile-butadiene-styrene terpolymers (ABS) or other heterogeneous polymer systems developed for improved toughness. Given the relative newness of these developments, we will limit ourselves here to some preliminary results on morphology development in some 

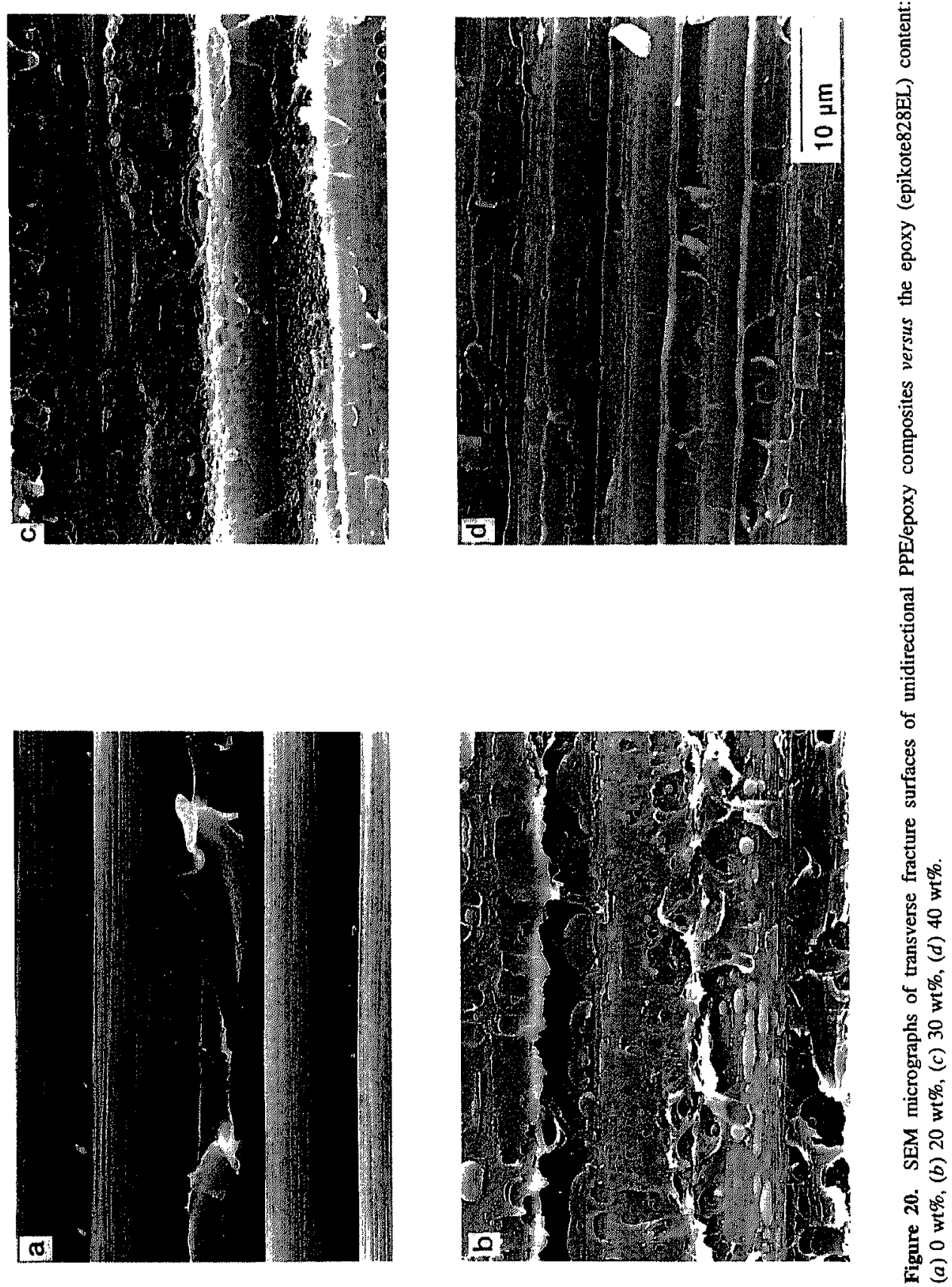


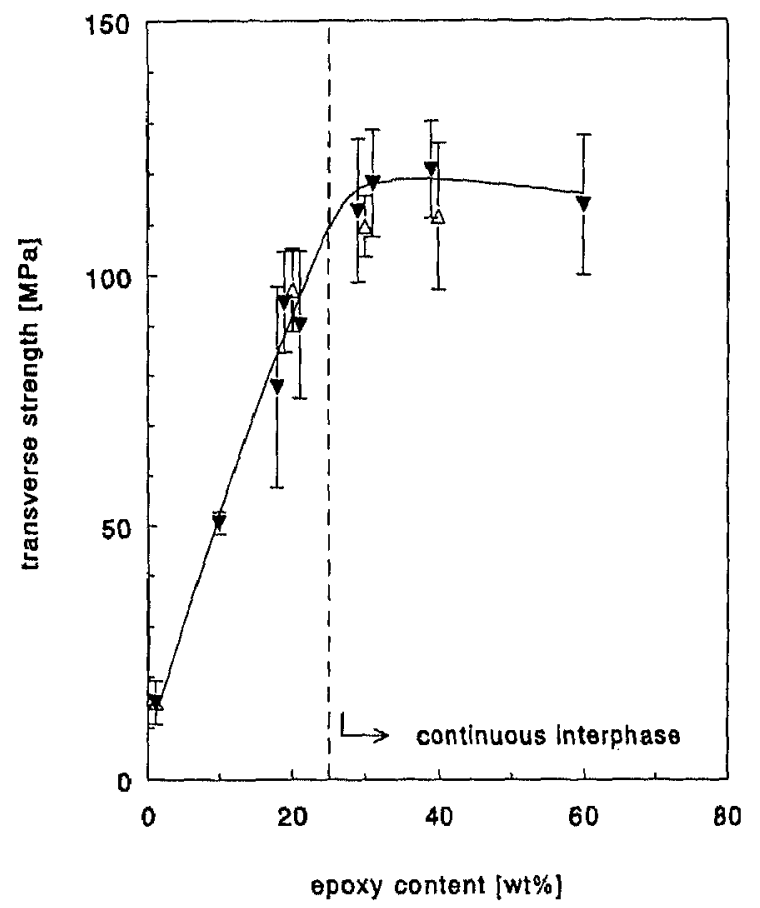

Figure 21. Transverse flexural strength of unidirectional PPE/epoxy composites with a fibre volume fraction of $50(\Delta)$ and $60 \%(\mathbf{v})$ versus the epoxy (DGEBA) content of the matrix.

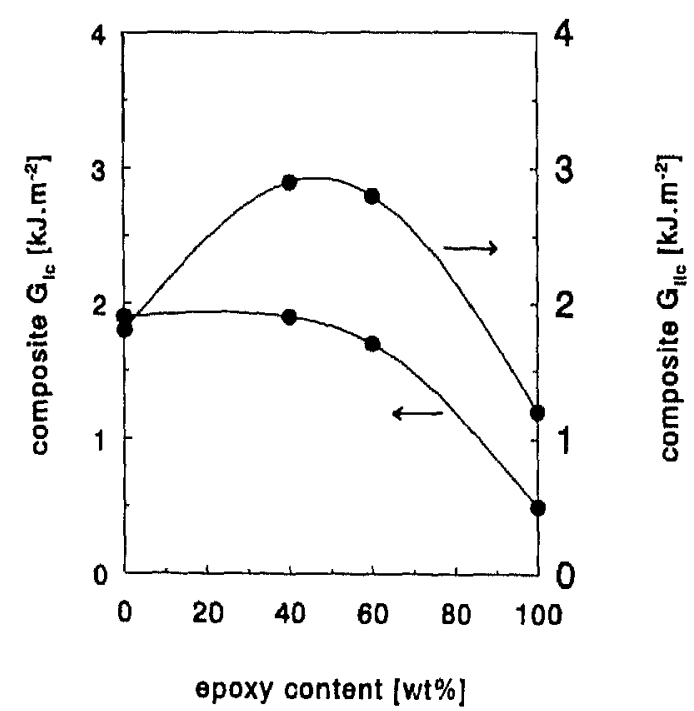

Figure 22. Critical strain energy release satc $G_{c}$ of carbon-fabric-reinforced composites (50 vol.\% fibres) versus matrix composition.

of these systems, where crystallization can often interfere with phase separation. Linear poly(ethylene)-styrene ( $\mathrm{PE} / \mathrm{St}$ ) is chosen as a model system, while as an alternative for the 
a)
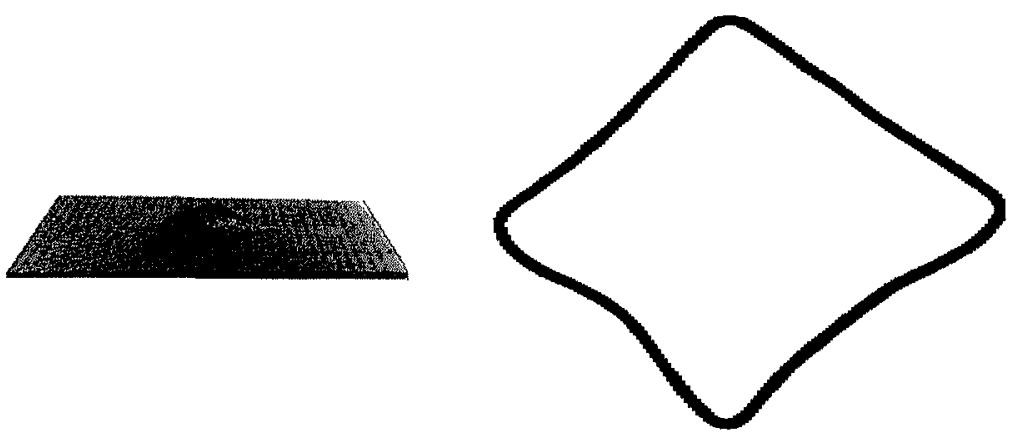

b)

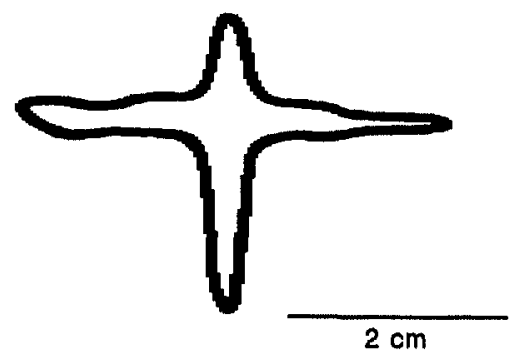

Figure 23. Tensile face damage and schematic representation of C-scan images of carbon fabric laminates (50 vol.\% fibres) impacted at an energy level of $9 \mathrm{~J}$ : (a) epoxy matrix, (b) PPE/epoxy matrix (40 wt\% epoxy).

reactive solvent styrene, that ultimately gives a brittle dispersion in the form of PS spheres, butyl-methacrylate (BMA) is investigated, since this yields a rubbery dispersion.

\subsection{Miscibility}

The miscibility of PE-St was measured by differential scanning calorimetry (DSC). Samples with different PE concentrations were transferred into high-pressure DSC sample pans. Different cooling rates were used to determine the onset of crystallization. For constructing the 'crystallization line' in the phase diagram, the onset of the crystallization was linearly extrapolated to a cooling rate of $0^{\circ} \mathrm{C} \mathrm{min}^{-1}$. For construction of the 'melting line', the temperature of the end of the melting endotherm was used as the melting temperature $T_{m}$. The melting temperature depression of a semicrystalline polymer/solvent system can be approximated by $[83]$

$$
\frac{1}{T_{m}}=\frac{1}{T_{m}^{0}}-\frac{R V_{2}}{\Delta H_{m} V_{1}}\left(\chi \phi_{1}^{2}-\phi_{1}\right)
$$

with $T_{m}$ and $T_{m}^{0}$ representing respectively the equilibrium melting temperature of the polymer in the solvent and the equilibrium melting temperature of the pure polymer, $\Delta H_{m}$ the melting enthalpy per monomer unit, and $\phi_{1}$ representing the volume fraction of the solvent. $V_{1}$ and $V_{2}$ represent the molar volume of the solvent and the polymer respectively and $\chi$ is the interaction parameter. The resulting phase diagram is depicted in figure 24 . There is no interference [84-88] with liquid-liquid demixing, indicating that styrene is a good solvent for poly(ethylene). 


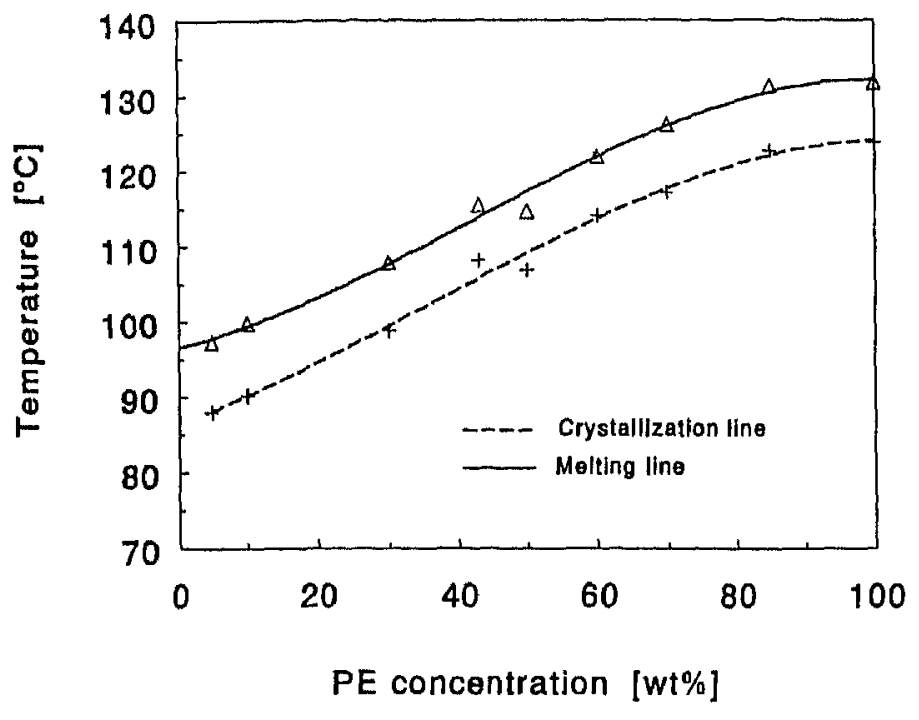

Figure 24. Phase diagram of $\mathrm{PE} / \mathrm{styrene}$ solutions.

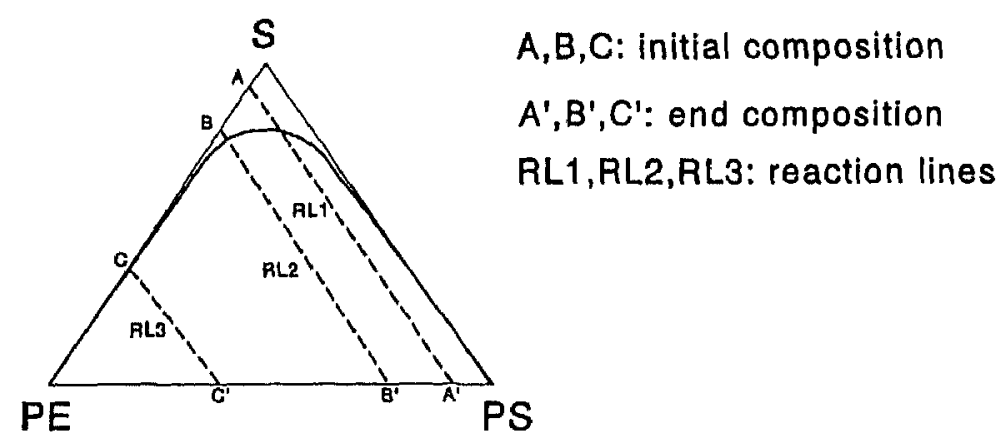
$A^{\prime}$ : PE dispersed in PS matrix
$B^{\prime}$ : Co-continuous structure
$C^{\prime}$ : PS dispersed in PE matrix

Figure 25. Schematic ternary phase diagram for PE/PS/styrene.

\subsection{Chemically induced phase separation (CIPS)}

Upon isothermal polymerization of the reactive solvent styrene, a third component (PS) is introduced in the initial homogeneous solution. Since PE and PS are immiscible over the whole composition range, it is clear that phase separation will occur. Unlike the PPEepoxy system, for which the chemically induced phase separation can be considered as an upward shift and a concurrent change of the shape of the cloud point curve, the chemically induced phase separation for the PE-St system has to be considered as following a reaction line in a ternary phase diagram, as depicted in figure 25 for the PE-St-PS system. The overall composition will follow such a reaction line. However, upon entering the two-phase 


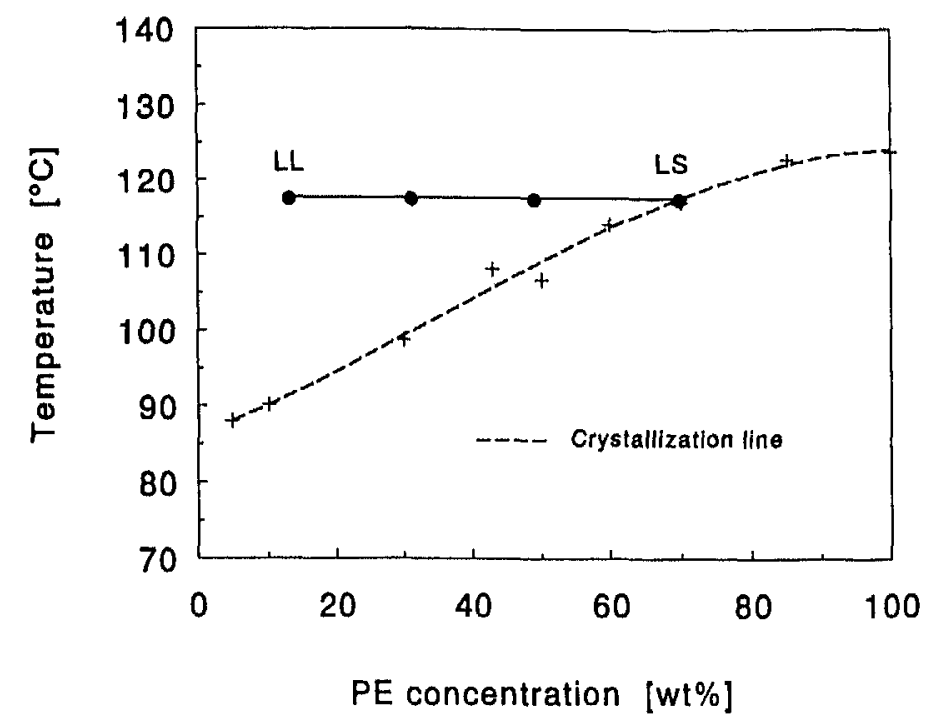

Figure 26. Schematic representation of the $L-S$ transition in the PE-rich phase.

region, i.e. crossing the binodal, phase separation will set in, resulting in PE-rich and PS-rich regions. Depending on the polymerization temperature, interference of phase separation with crystallization can take place, making the precise choice of the polymerization temperature of utmost importance (see figure 26).

Interestingly, even at extremely low polymer fractions, it is expected that the polymer will form the continuous phase, given the complete immiscibility of the resulting polymer systems PE-PS.

\subsection{Morphology development}

With the aid of simultaneous time-resolved small- and wide-angle x-ray scattering (SAXS and WAXS), performed at station 8.2 of the Synchrotron Radiation Source (SRS) in Daresbury, UK, morphology development could be investigated. SAXS and WAXS data were collected during in situ polymerization at two temperatures. The SAXS results for 20 and $60 \mathrm{wt} \% \mathrm{PE}$, polymerized at $121^{\circ} \mathrm{C}$, are presented in figures $27(a)$ and $28(a)$ respectively, as three-dimensional plots of Lorentz corrected intensity, $I q^{2}$, versus the scattering vector $q=(4 \pi / \lambda) \sin (\theta / 2)$, where $\theta$ is the scattering angle, versus time. For extracting information about the periodicity of the structure, a one-dimensional spacing of the structure can be derived from the maximum in the Lorentz corrected plot. The spacing can then be calculated using Bragg's law

$$
d=\lambda / 2 \sin q_{\max }=2 \pi / q_{\max }
$$

Clearly the onset of phase separation is recognized as well as the later start of crystallization when the polymerization temperature is below the crystallization temperature (see figures $27(b)$ and $28(b)$ ). 


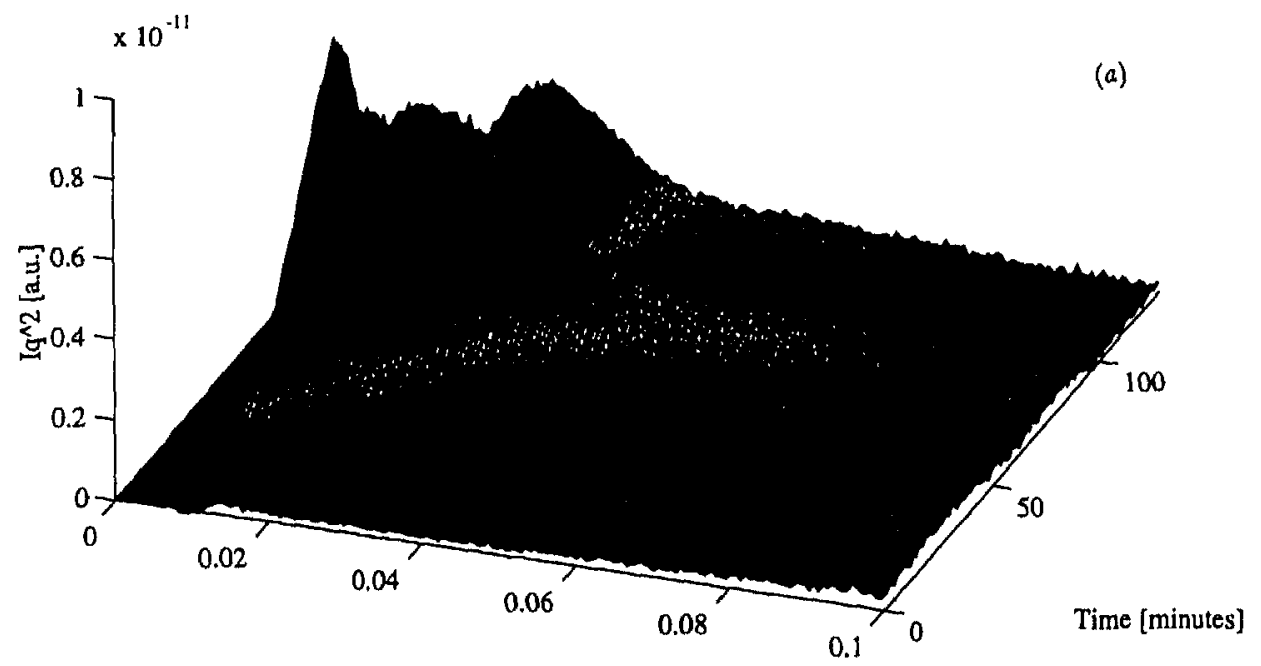

$q[1 / \AA]$

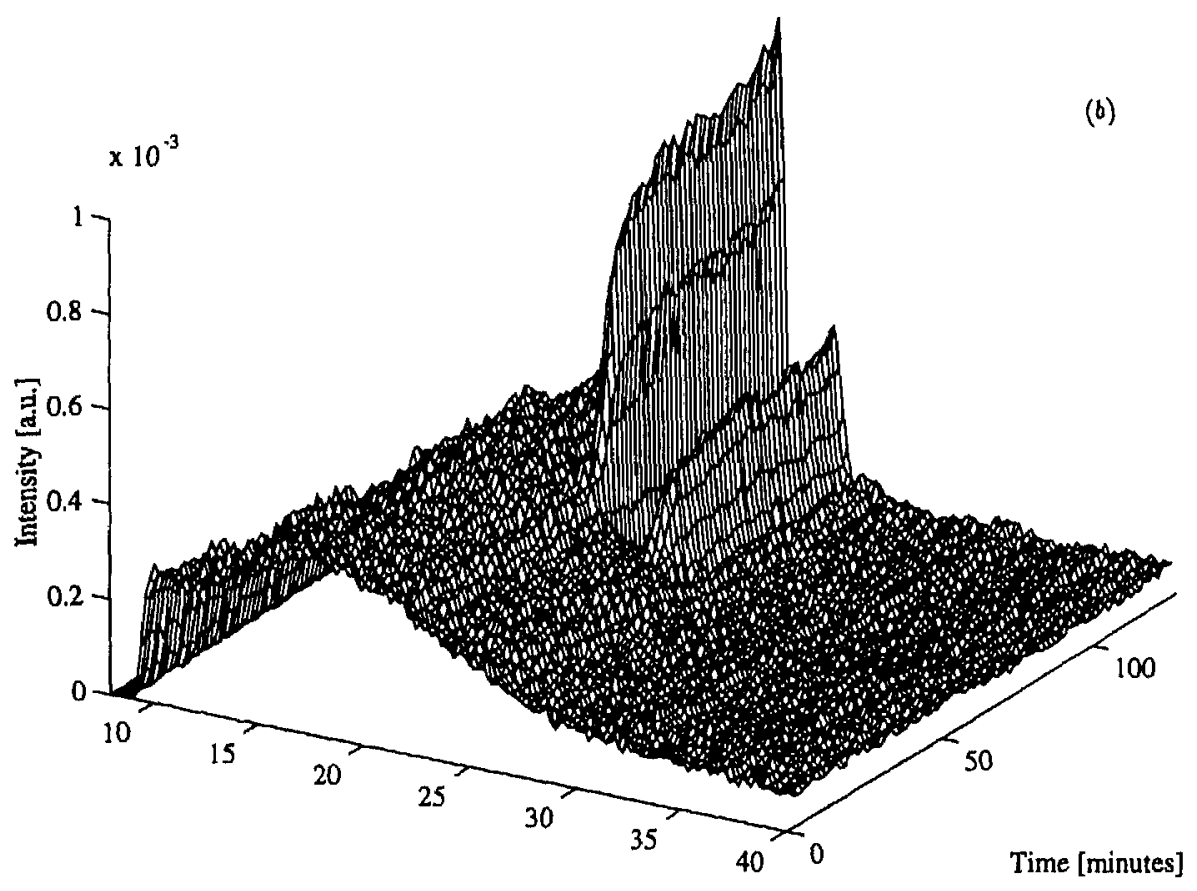

2 theta

Figure 27. X-ray scattering data for the $20 \mathrm{wt} \% \mathrm{PE}$ in styrene solution polymerized at $121^{\circ} \mathrm{C}$ : (a) Lorentz corrected SAXS data as three-dimensional plots of intensity, $I(q) q^{2}$, versus scattering vector, $q$, versus time $t$ and (b) WAXS data as three-dimensional plots of intensity, $I$, versus scattering angle, $2 \theta$, versus time $t$. 


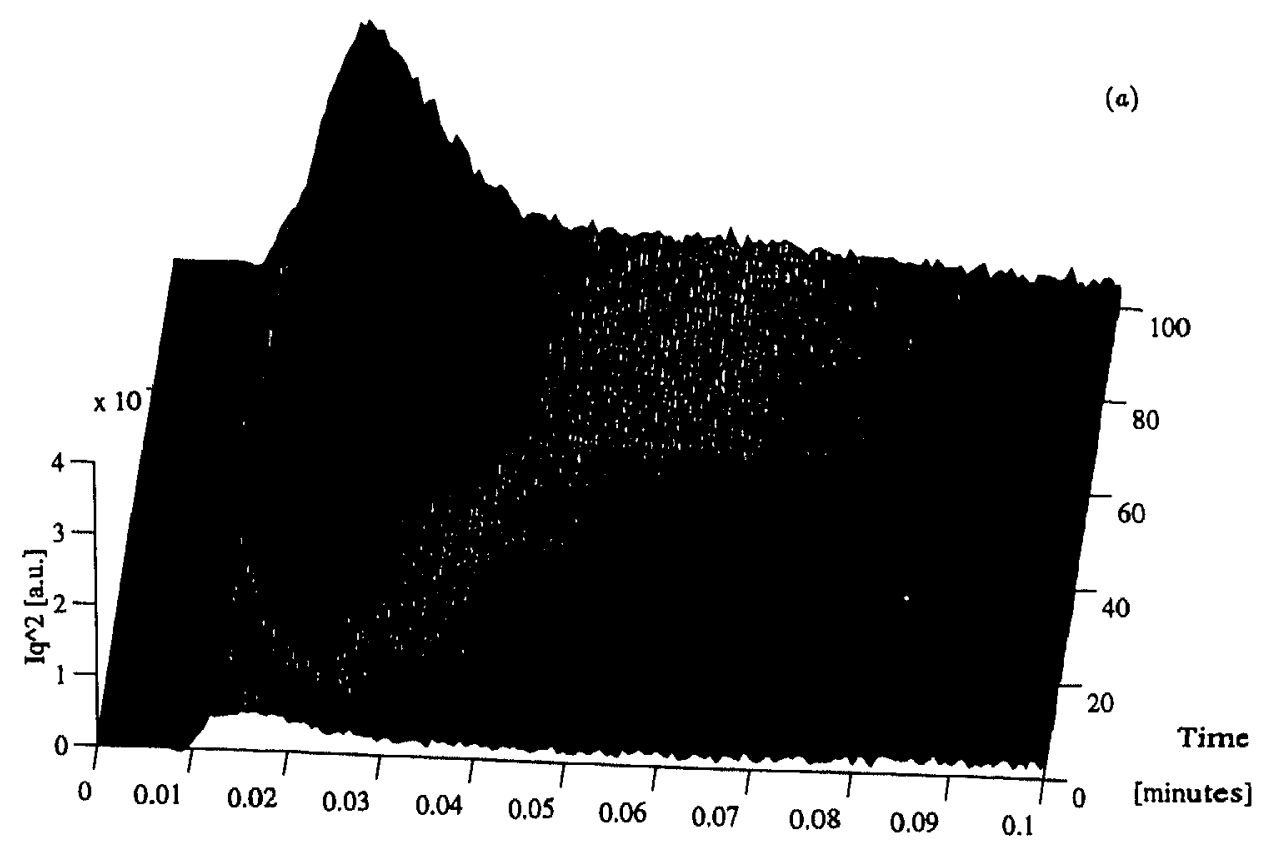

$q[1 / \AA]$

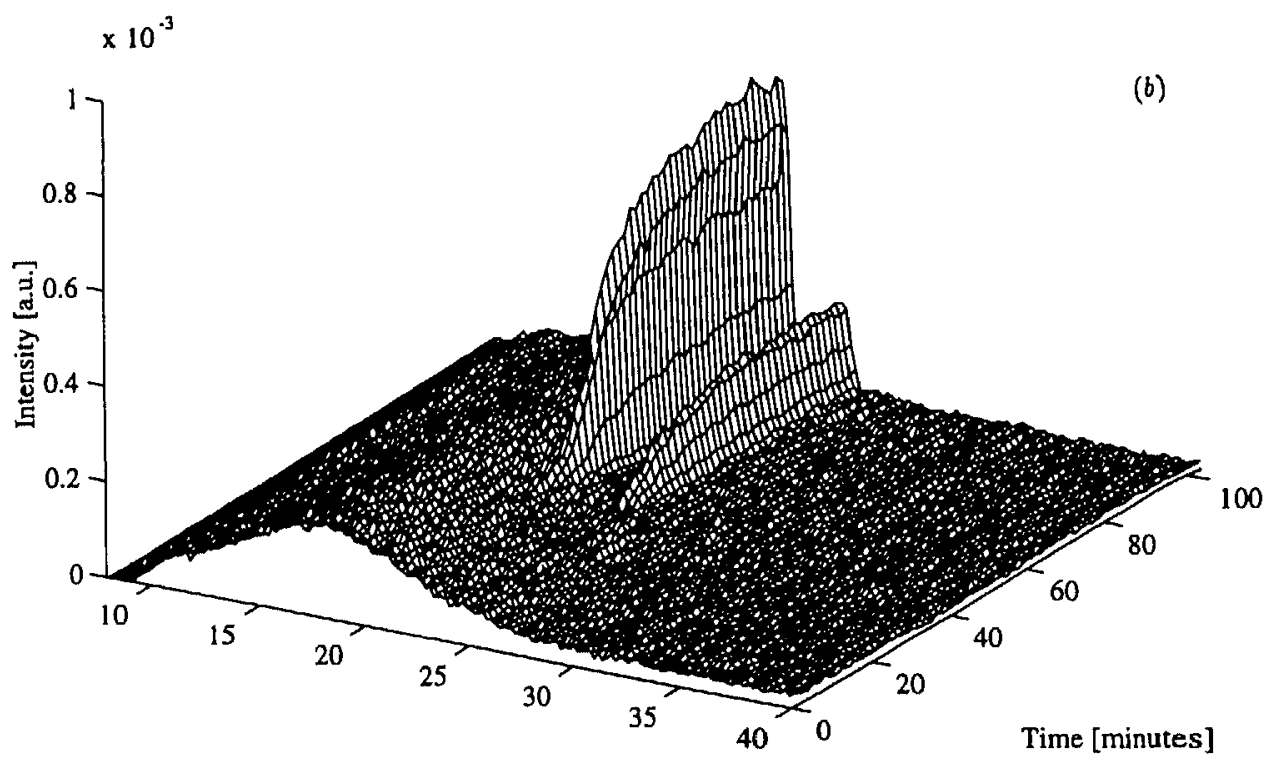

2 theta

Figure 28. X-ray scattering data for the $60 \mathrm{w} / \% \mathrm{PE}$ in styrene solution polymerized at $121^{\circ} \mathrm{C}:(a)$ Lorentz corrected SAXS data as three-dimensional plots of intensity, $l(q) q^{2}$, versus scattering vector, $q$, versus time $t$ and $(b)$ WAXS data as three-dimensional plots of intensity, $I$, versus scattering angle, $2 \theta$, versus time $t$. 

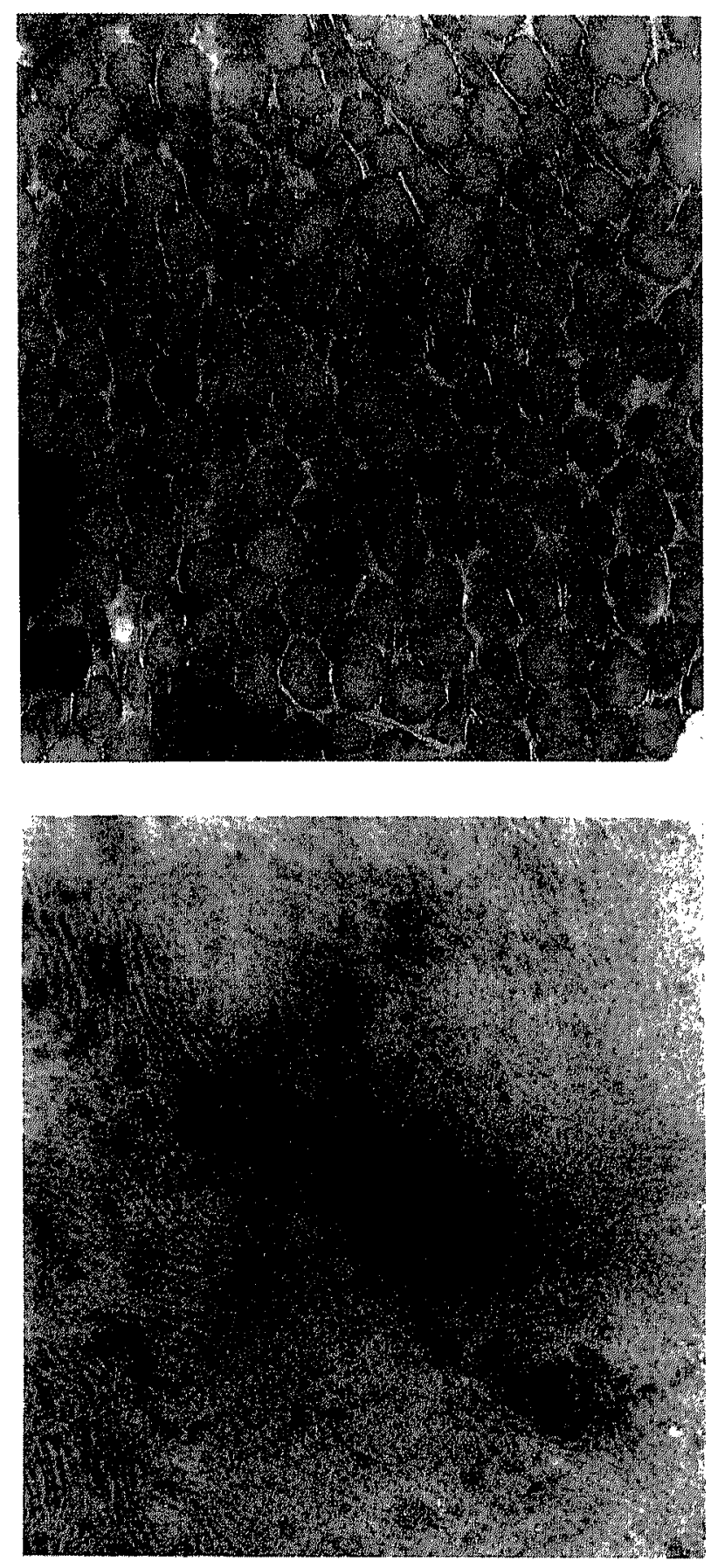

Figure 29. TEM micrographs of PE/PS blends with a PE content of $20 \mathrm{wt} \%$ (top) and $60 \mathrm{wt} \%$ (bottom), polymerized at $121^{\circ} \mathrm{C}$. 


\section{Morphology}

Transmission electron microscopy (TEM) pictures of the resulting morphologies confirm the $x$-ray scattering results. Some illustrative examples are given in figure 29.

Typically $200 \mathrm{~nm}$ sized structures are found with many details. The individual lamellae of the folded chain PE crystals form the continuous phase, already at about $6 \%$ PE present. By replacing the reactive solvent St by BMA similar structures are found, and a wide range of mechanical properties result from stiff and brittle for PE-PS to rubbery and tough for EPDM-BMA [8].

\section{Concluding remarks}

It has been shown that the use of reactive solvents in the processing of both intractable and tractable thermoplastic polymers offers a flexible route to extend the processing characteristics of existing polymers to far beyond their existing limits. The method was only demonstrated by using two model systems, PPE-epoxy and PE-St, but it was also implicitly shown that many more challenges still exist. In our laboratory, we are now developing a number of high-performance and low-priced composite systems, based on different thermoplastic matrices. Moreover, we aim at the intrinsic flexibility of this new processing method in order to develop heterogeneous polymer systems with unique, and often extremely fine, morphologies, that otherwise cannot be obtained for instance with the more standard compounding and blending techniques. This can be of utmost importance for obtaining the ultimate properties of polymeric materials in terms of toughness [74]. Although the method is basically limited to end-use applications, thus introducing chemistry to the end-user, some ways out of this obvious disadvantage have been pointed out. Of course, further developments in this direction should be restricted to tractable polymer systems, at least if real flow, and thus a relatively low viscosity, is prerequisite, for example in injection moulding. For thermoforming, fewer restrictions are present and the necessity of chemistry can be restricted to the prepreg manufacturer. Finally, with respect to the more classical reactive processing routes, clear advantages exist, mainly because the main properties of the resulting product are determined by the, originally dissolved, thermoplastic polymer and only in the second instance by the converted solvents that end up as a dispersed phase, or interphase when polar surfaces are present, in this continuous thermoplastic matrix.

\section{Acknowledgments}

The authors wish to thank a number of companies who financially supported this work and a number of people who helped to develop these new systems: DSM Research (Ir Pieter Greidanus), GEP Bergen op Zoom (Professor Jan Bussink, Dr Wim Sederel), De Regt Cable Dordrecht (Ir Nick O'Hear), BDM Arnhem (Drs Rene Pas), Daresbury Station 8.2 (Dr Tony Ryan, Dr Wim Bras) and, finally, Dr Sanjay Rastogi (TUE).

\section{References}

[1] Venderbosch R W, Meijer H E H and Lemstra P J 1994 Polymer 354349

[2] Venderbosch R W, Meijer H E H and Lemstra P J 1995 Polymer 361167

[3] Venderbosch R W, Meijer H E H and Lemstra P J 1995 Polymer 362903

[4] Venderbosch R W, Meijer H E H and Lemstra P J 1996 Polymer at press

[5] Venderbosch R W, Meijer H E H and Lemstra P J 1996 Polymer at press 
[6] Venderbosch R W, Nelissen J G L, Meijer H E H and Lemstra P J 1993 Makromol. Chem. Macromol. Symp. 7573

[7] Goossens J G P, Rastogi S and Meijer H E H in preparation

[8] Goossens J G P, Meijer H E H and Lemstra P J Polymer submitted

[9] Jansen B J P unpublished results

[10] Qipeng G, Xinsheng P and Zhiji W 1991 Polymer 3253

[11] Gomez C M and Bucknall C B 1993 Polymer 342111

[12] Nichols M E and Robertson R E 1994 J. Polym. Sci, Polym. Phys. 321607

[13] Kim J and Robertson R E 1993 Adv. Chem. Ser. 233427

[14] Chao H S and Whalen J M 1993 J. Appl. Polym. Sci. 491537

[15] Pearson R A and Yee A F 1993 J. Appl. Polym. Sci. 481051

[16] Pearson R A and Yee A F 1993 Polymer 343658

[17] Venderbosch R W, Meijer H E H and Lemstra P J 1994 Polymer 354349

[18] Venderbosch R W, Meijer H E H and Lemstra P J 1995 Polymer 362903

[19] Diamant J and Moulton R J 1984 28th National SAMPE Symp. (3-5 April 1984) p 422

[20] Bucknall C B and Gilbert A H 1989 Polymer 30213

[21] Chen H H and Schott N R 1992 Polym. Prep. 33495

[22] Chen H H and Schott N R 1992 Polym. Prep. 33498

[23] Hourston D J, Lane J M and MacBeath N A 1991 Polym. Int. 2617

[24] Cho J B, Hwang J W, Cho K, An J H and Park C E 1993 Polymer 344832

[25] Di Liello V, Martucelli E, Musto P, Ragosta G and Scarinzi G 1993 Angew. Makromol. Chem. 21393

[26] Hourston D J and Lane J M 1992 Polymer 331379

[27] Biolley N, Pascal T and Sillion B 1994 Polymer 35558

[28] Ohsako T, Nagura K and Nozue I 1993 Polymer 345080

[29] Qipeng G 1993 Polymer 3470

[30] Noshay A and Robeson L M 1974 J. Polym. Sci., Polym. Chem. 12689

[31] Clark J N, Daly J H and Garton A J 1984 J. Appl. Polym. Sci. 293381

[32] Moore D R and Mathias L J 1987 Polym. Prep. 2852

[33] Bucknall C B and Partridge I K 1983 Polymer 24639

[34] Bucknall C B and Partridge I K 1984 Composites 15129

[35] Bucknall C B and Partridge I K 1986 Polym. Eng. Sci. 2654

[36] Muraki T, Takeo A and Hirata M 1986 Materials Science Monographs vol 35, ed K Brunsch, H D Gölden and $C \mathrm{M}$ Herkert (Amsterdam: Elsevier) $\mathrm{p} 163$

[37] Wang Z, Chen D and Liu X 1987 J. Adhes. 23201

[38] Raghava R S 1987 J. Polym. Sci., Polym. Phys. Edn. 251017

[39] Raghava R S 1988 J. Polym. Sci., Polym. Phys, Edn, 2665

[40] Almen G R, Mackenzie P, Malhotra V, Maskell R K, McGrail P T and Sefton M S $1988 \mathrm{lmt}$. SAMPE Technical Conf. Ser. vol 20, ed H L Chess, S P Prosen, J W Davis and J A Heth (Covina: Society for the Advancement of Materials and Process Engineering) p 46

[41] Yamanaka K and Inoue T 1989 Polymer 30662

[42] MacKinnon A J, Jenkins S D, McGrail P T and Pethrick R A 1992 Macromolecules 253492

[43] MacKinnon A J, Jenkins S D, McGrail P T and Pethrick R A Polymer 343252

[44] Kim B S, Chiba T and Inoue T 1993 Polymer 342809

[45] Kinloch A J, Yuen M L and Jenkins S D 1994 J. Mater. Sci. 293781

[46] Hedrick J L, Yilgör I, Wilkes G L and McGrath J E 1885 Polym. Bull. 13201

[47] Hedrick J L, Yilgör I, Jurek M, Hedrick J C, Wilkes G L and McGrath J E 1991 Polymer 322020

[48] Pak S J, Lyle G D, Mercier R and McGrath J E 1993 Polymer 34885

[49] Fu Z and Sun Y 1989 Chin. J. Polym. Sci. 7367

[50] Bauer R. S, Stenzenberger H D and Robmer W 1989 Science of Advanced Materials and Process Engineering Series vol 34, ed G A Zakrzewski, D Marenko, S T Peters and C D Dean (Covina: Society for the Advancement of Materials and Process Engineering) p 899

[51] Bauer R S, Stenzenberger H D and Römer W 1990 Science of Advanced Materials and Process Engineering Series vol 35 (Covina: Society for the Advancement of Materials and Process Engineering) p 395

[52] lijima T, Tochimoto T and Tomoi M 1991 J. Appl. Polym. Sci. 431685

[53] Bennet G S, Farris R J and Thompson S A 1991 Polymer 321633

[54] Fox T G 1956 Bull. Am. Phys, Soc. 2123

[55] Arnauts J and Berghmans H 1987 Polymer Comm. 2866

[56] Vandeweerdt P, Berghmans H and Tervoort Y 1991 Macromolecules 243547 
[57] Verchère D, Sautereau H, Pascault J P, Moschiar S M, Riccardi C C and Williams R J J 1989 Polymer 30 107

[58] Verchère D, Sautereau H, Pascault J P, Moschiar S M, Riccardi C C and Williams R J J 1990 J. Appl. Polym. Sci. 41467

[59] Verchere D, Pascault J P, Sautereau H, Moschiar S M, Riccardi C C and Williams R J J 1991 J. Appl. Polym. Sci, 42701

[60] Moschiar S M, Riccardi C C, Williams R J J, Verchère D, Sautereau H and Pascault J P 1991 J. Appl. Polym. Sci. 42717

[61] Verchère D, Pascault J P, Sautereau H, Moschiar S M, Riccardi C C and Williams R J J 1991 J. Appl. Polym. Sci. 43293

[62] De Graaf L 1994 PhD Thesis Twente University of Technology, The Netherlands

[63] Aubert J H 1990 Macromolecules 231446

[64] Lifshitz I M and Slyozov V V 1961 J. Phys. Chem. Solids 1935

[65] Siggia E D 1979 Phys. Rev. A 20595

[66] McMaster L P 1975 Adv. Chem. Ser. 14243

[67] Voigt-Martin I G, Leistner K H, Rosenau R and Koningsveld R 1986 J. Polym. Sci., Polym. Phys. 24723

[68] Jansen B J P unpublished results

[69] Aronhime M T and Gillham J K 1986 Adv. Polym. Sci. 7883

[70] LeMay J D and Kelly F N 1986 Adv. Polym. Sci. 78115

[71] Levita G 1989 Adv. Chem. Ser. 22293

[72] Pearson R D and Yee A F 1989 J. Mater. Sci. 242571

[73] Fischer M 1992 Adv. Polym. Sci. 100313

[74] Van der Sanden M C M and Meijer H E H 1993 Polymer 345063

[75] Bos H L and Nusselder J J H 1994 Polymer 352793

[76] Morgan R J, Kong F M and Walkup C M 1984 Polymer 25375

[77] Davies P 1992 Report of European Structural Integrity Society, Polymers and Composites Task Group (Ecole Polytechnique Federale de Lausanne, Switzerland)

[78] Cantwell W J and Morton J 1991 Composites 22347

[79] Odagiri N, Muraki T and Tobukuro K 1988 Science of Advanced Materials and Process Engineering Series vol 33, ed G Carrilo, E D Newell, W D Brown and P Phelan (Covina: Society for the Advancement of Material and Process Engineering) p 272

[80] Recker H G, Altstädt V, Eberle W, Folda T, Gerth D, Heckmann W, Ittemann P, Tesch H and Weber T 1990 SAMPE J. 2673

[81] Prichard J C and Hogg P J 1990 Composites 21503

[82] de Kok J M M 1995 PhD Thesis Eindhoven University of Technology

[83] Flory P J 1953 Principles of Polymer Chemistry (Ithaca, NY: Cornell University Press)

[84] Richards R B 1946 Trans. Faraday Soc. 4210

[85] Roginova L Z and Slonimskii G L 1974 Russian Chem. Rev. 431102

[86] Berghmans H, Donkers A, Frenay L, Stoks W and De Schryver F E 1987 Polymer 2897

[87] Stoks W, Berghmans H, Moldenaers P and Mewis J 1988 British Polym. J. 20361

[88] Stoks W and Berghmans H 1991 J. Pol. Sci.: Part B: Polym. Physics 29609 